\title{
CREATIVITY AND ORGANISATIONAL EFFICIENCY: EMPIRICAL EVIDENCE FROM PRIVATE ORGANISATIONS IN NIGERIA
}

\author{
Henry INEGBEDION (D) ${ }^{1, *}$, Emmanuel INEGBEDION ${ }^{2}$, Eseosa OBADIARU ${ }^{3}$, \\ Abiola ASALEYE (D) ${ }^{4}$, Sarah ADEYEMI ${ }^{5}$, Damilola ELUYELA ${ }^{6}$ \\ ${ }^{1}$ Department of Business Studies, College of Business and Social Sciences, Landmark University, \\ KM 4, Ipetu Road, PMB 1001, Omu-Aran, Nigeria \\ ${ }^{2}$ Physical Planning Department, National Broadcast Academy, \\ 1A, Adekunle-Fajuyi Way, GRA, Ikeja, PMB 12504, Lagos, Nigeria \\ 3, ${ }^{5}$ Department of Accounting, College of Business and Social Sciences, Landmark University, \\ KM 4, Ipetu Road, PMB 1001, Omu-Aran, Nigeria \\ ${ }^{4}$ Department of Economics, College of Business and Social Sciences, Landmark University, \\ KM 4, Ipetu Road, PMB 1001, SDG 17, Omu-Aran, Nigeria \\ ${ }^{6}$ Department of Accounting and Finance, College of Business and Social Sciences, Landmark University, \\ KM 4, Ipetu Road, PMB 1001, Omu-Aran, Nigeria
}

Received 9 April 2020; accepted 26 May 2021

\begin{abstract}
The study investigated creativity and organisational efficiency in Nigerian private organisations to ascertain the extent to which workforce creativity enhances organisational efficiency. The quantitative methodology was employed and the research design was a cross-sectional survey. Stratified sampling was employed in selecting respondents from ten multinational companies across the six geopolitical zones in Nigeria. Research data were elicited from the respondents with the help of a structured questionnaire. The question response format of items addressing the research questions in the questionnaire were of the five-point Likert scale. The study used measurement items related to the extant literature for all the measures. Structural equation modeling was employed in data analysis with organisational efficiency serving as the latent variable while creativity constructs served as the measured variables. Results show that three out of the four constructs of creativity were significant predictors of creativity Thus, the competitive environment, social capital and technological factors influence creativity and that creativity predicts organisational efficiency.
\end{abstract}

Keywords: competitive environment, creativity, organisational efficiency, social capital, technological factors.

\section{Introduction}

Creativity, a key driver of economic growth, could serve as a critical catalyst for organisational efficiency and job creation in Nigeria and other less developed countries in the world. "Creativity has always been at the heart of the human endeavour. Allied to innovation, which creates unexpected value, it is now recognized as central to organizational performance"

${ }^{\star}$ Corresponding author. E-mail: inegbedion.henry@lmu.edu.ng

Copyright (c) 2021 The Author(s). Published by Vilnius Gediminas Technical University

This is an Open Access article distributed under the terms of the Creative Commons Attribution License (http://creativecommons. org/licenses/by/4.0/), which permits unrestricted use, distribution, and reproduction in any medium, provided the original author and source are credited. 
(Serrat, 2009, p. 6). It is believed that the ability to exploit the creative and innovative potentials of people and convert such to new things is critical to organizational efficiency and thus, competitiveness:
"The shift to knowledge economies has been abrupt and there is a flurry of interest in creativity and innovation in the workplace. Innovation is considered, quite simply, an imperative for organizational survival. It may even be the key to some of the biggest challenges facing the world, such as global warming and sustainable development" (United Nations, 2008, p. 5).

Abundant literature is available on creativity as the concept has been examined from various dimensions by various authors. Some of the aspects examined in the literature include mental models and creative problem solving (Mumford et al., 2012), organisational creativity (James \& Drown, 2012), componential theory of creativity (Amabile, 2012), the role of creativity and innovation in entrepreneurship (Babu et al., 2013), a road map to business success and growth (Xiao Hua et al., 2015), a viable tool for entrepreneurial development (Oluwadare, 2015), the interaction between social capital, creativity and efficiency in organizations (Sözbilir, 2018) and innovation effectiveness and productive efficiency (Stojcic et al., 2018), among others.

Organisational efficiency is a very important concept as it is viewed as a major determinant of organisational growth, profitability and competitiveness. An efficient organisation can compete favourably in the industry and thus expand, with the attendant job creation potentials. Efficiency was the major emphasis of the scientific management era. Aubyn et al. (2009, p. 5) see efficiency as the relationship between inputs and outputs of a given activity. In this regard, efficiency refers to the rate at which outputs compare with inputs; the lower the ratio of input to outputs the more efficient the system or organisation. It is for this reason that Farrell (1957) sees efficiency as a success in producing as much output as possible from available input. More succinctly, efficiency is related to the judicious utilisation of limited resources such as time, finance, space, and energy, for the intended task or to achieve the objectives (Yampolskiy, 2013). This implies that efficiency is all about the optimum allocation of resources. To this end, efficiency has practical application in all spheres of human endeavour and in all strata, whether public or private. While the provision of high quality of service is the primary functions of government, efficiency can be achieved in areas such as taxation, spending, regulation and policymaking while satisfaction of customers' needs through enhanced service level and service delivery are the aspects of organisational efficiency in the private sector. Efficiency is achievable when resource allocation is optimised; that is, when inputs are judiciously employed to achieve greater outputs. In this regard, efficiency can be viewed as doing things right and consistently doing things right for optimal results. This is not the same thing as effectiveness, which means doing the right thing. As simple as efficiency, exemplified by the relationship between input and output, appears to be, achieving efficiency has been a nightmare for many organisations, especially public sector organisations (Mihaiu et al., 2010). Does this deficiency have anything to do with the dearth of creative individuals in such organisations?

Making grassroots innovations as a basic building block for societal transformation is a valid and practical strategy for development and promoting creativity in the organisation can stimulate creative thinking among the employees in the organisation and thus enhance strategic 
positioning of the organisation (Gupta, 2013). The question then arises, to what extent does creativity influence organisational efficiency? Amabile's (1983, 2012), Sternberg's (Sternberg \& Lubart, 1991, 1995) and Kash's (1989) theories indicate that creative individuals require some personality characteristics and a supportive environment. Among other institutions, the organisation to which a person belongs can provide a supportive environment for creativity if it promotes creativity. To this end, this study sought to investigate the extent to which creativity can facilitate organisational efficiency in Nigeria. In other words, the study sought to investigate how creativity can contribute to the enhancement of organisational efficiency.

There is no doubt that the technologically advanced counties of the world such as in Europe, America, and in Asia, among others, are far ahead of the sub-Saharan African countries in terms of economic development and the economic welfare of their citizens. The gap between the developed countries, as they are often called, and the developing/underdeveloped countries is traceable to the level of creativity and innovation of their industries and employees. There is empirical evidence that international cultures have implications on the creative potentials of citizens and industries across nations (Shao et al., 2019; Liu \& Silva, 2018; Boix-Domènech \& Rausell-Köster, 2018; Lubart, 2010). Boix-Domènech and Rausell-Köster (2018) quantified the direct and indirect impacts of the creative industry and concluded that the creative industry not only has a direct impact on the employment and production, but also contributes to the technological progress and long-term development of the European Union (EU). He attributed most of the contribution of the creative industries is to the creative service industries. The conspicuous divide between the developed and the underdeveloped countries of the world is a consequence of their level of creativity and innovation. To this end, stimulating creativity and innovation can prove useful in bridging the gap between the developed and underdeveloped countries since creativity can help in enhancing organisational efficiency and thus economic growth.

In view of the foregoing, this study examines the extent to which creativity can enhance organisational efficiency in Nigerian private organisations. Specifically, it sought to determine: the extent to which technological capital (an organisation's technological capital as well as an organisation's information system), competition (competitive dominance, competitors' product pricing), social capital (collaborative work teams, employees' freedom in taking initiatives, norms of actively sharing ideas) and personality (level of education, personality traits, feelings of inferiority) influence creativity and the extent to which creativity influences organizational efficiency in Nigeria.

\section{Literature review}

In modern organisations, which have become highly competitive, owing to globalisation, creativity is viewed as becoming increasingly indispensable to organisational efficiency and so is innovation.

\subsection{Conceptual review}

Creativity is the generation of new and useful ideas (Babu et al., 2013; Xiao Hua et al., 2015; Mansur, 2015; Oluwadare, 2015; Porter et al., 2007). It is the production of a novel product or 
solution to an open-ended task. A creative person is one who can combine or rearrange ideas in a unique fashion". From diverse origins such as mysticism and divine inspiration, creativity has evolved to become a key performance contributor to organisations' adaption to changing environments. Creative ideas must have the potential to assist in accomplishing the desired goals. Creative ideas must be appropriate; that is, of potential value towards accomplishing desired goals, if they are to be useful. These ideas, according to James and Drown (2012), may reflect either a recombination of existing materials or an introduction of new materials to the organization. Specifically, in strategic positioning, a firm can seek cost leader or differentiation or focus or focus cost leadership or focused differentiation. Any of the above five options requires creative inputs to be successfully actualised. In this regard, efficiency refers to the firm's ability to implement the strategies in a cost-effective manner. It is this cost effectiveness that will enable the firm to price its products favourably and competitively.

Amabile and Mueller (2008) believe that selection among alternatives is important and that the task to be completed must be open-ended, rather than having a single, obvious solution. Irrespective of the fact that different people have tried to qualify creative activity differently, it has continued to be viewed as very critical to the capacity of modern organizations to innovate. In organizational contexts, creativity has been viewed as the production of high-quality, original, and elegant solutions to problems, thus portraying it as performanceoriented and capable of solving problems useful for decisions-making owing to high levels of cognitions involved (Mumford et al., 2012). According to George,

"Novelty for novelty's sake, therefore, is not the same thing as creativity. Similarly, effective problem solving is certainly useful in organizations but does not necessarily reflect creativity. For problem-solving to be creative, generated solutions must be novel" (2007, p. 16).

\subsubsection{Innovation}

According to Zahra and Covin (1994), innovation is widely considered as the lifeblood of corporate survival and growth. Innovation is recognised to play a central role in creating value and sustaining a competitive advantage. Bessant et al. (2005) emphasise that innovation represents the core renewal process in any organization; unless it changes what it offers the world and the way it creates and delivers those offerings, it risks its survival and growth prospects. Innovation is tightly coupled to change, as organizations use it as a tool to influence an environment or due to their changing environments (internal and external) (Damanpour, 1991).

\subsubsection{Creativity versus innovation}

Oldham and Cummings see creativity as distinct in the literature from innovation because while

"innovation is commonly regarded as the successful implementation of creative ideas and its acceptance by various stakeholders in organizations; creativity is considered a necessary, but not sufficient pre-condition for innovation" (1996, p. 611).

The innovation literature often refers to ideation processes as the "fuzzy front end" of innovation, reflecting an unclear understanding of creativity as an initial process step. Creative 
individuals generate new ideas that are novel, useful and appropriate for the competitive advantage of their organisations in particular and their economies in general; thus, it can be argued that creativity is the precursor to innovation. Ideas that are not consistent with novelty, appropriateness and usefulness for competitive advantage remain simply as ideas. The process of ideation and selection has been conceptually modelled after Darwinian evolutionary theories, in which ideas mutate freely; however only those ideas that are well adapted to the host environment survive (Mumford et al., 2012).

\section{Empirical review}

This section investigates empirical evidence from extant studies on the hypothesized relationships between the dependent and independent variables of the study.

\subsection{Technological development and creativity}

World Economic Forum (2018) investigated how emerging technologies affect creativity and what is their impact on creativity. It was concluded that given the dynamic nature of the maturity of different technologies at present, it is a bit premature to categorically state how they will change the creative economy. Consequently, they outlined opportunities and concerns for each technology and present suggestions where attention was concentrated. Bonnardel and Zenasni (2010) investigated the impact of technology on creativity in design to present a new angle of reflection in the field of creative design. The approach was centred on designers' cognitive processes. The results contributed to empirical studies on how technologies enhance creativity through the effective facilitation of designers' activities.

Gangadharbatla (2010) examined how technology component can serve as a modified system approach to creative thought. The article outlines how technology influences individual, society, and the domain, and makes a case for the revision of the original model to include the technology component. The proposed changes to the system are illustrated and the implications of the proposed modifications to the creative process are discussed. Müller and Ulrich (2013) reviewed the literature on creativity and information systems in a hypercompetitive environment to summarize how to stimulate creativity and innovation in contemporary organizations. They employed Mel Rhodes' 4-Ps model (1961) to explain the relationship between creative environments and the people, products, and processes. Based on an intensive review of 110 journals on the list of Journal of the Association for Information Systems, with particular focus on eighty-eight; they offered insights into how creativity can be stimulated and supported through adequate attention to each of these components. Given the foregoing, we hypothesized that:

$H_{0} 1$ : There is no significant relationship between an organization's technological capital and creativity.

\subsection{Competitive pressure and creativity}

Meutia and Ismail (2017) investigated how competitive pressure influences the innovative creativity and competitiveness of batik small and medium-sized enterprises in Indonesia. The 
survey method was employed. Purposive sampling technique was used to select 168 respondents, based on the frequency of exporting batik into foreign countries. Data were analysed using structural equation modeling (SEM). Results showed that competitive pressure does not affect creativity skills but affects the ability to adapt to business environment change. Because of the foregoing, we hypothesized that:

$\mathrm{H}_{0}$ 2: There is no significant relationship between competition (competitors' dominance and competitive product pricing) and creativity.

\subsection{Social capital and creativity}

Paramitha and Indarti (2014) investigated how the support of the environment influences creativity using work and non-work environment as the environment support. They employed a survey design and elicited data from 132 employees (editorial staffs) working in the mass media industry in the Indonesian context. The results show that co-workers' support significantly influences the creativity of the employees. Intrinsic motivation was also found to have a partial influence on the relationship between the support from co-workers and creativity. Dehnavieh et al. (2010) investigated the factors influencing creativity and innovation of the senior managers of Iran University of medical sciences to determine the important individual and organizational factors that influence senior managers' creativity and innovation. They employed a questionnaire to elicit data from 66 managers. Results indicated that organisational factors had a significant influence on the creativity of the people investigated.

Jamshidi and Kenarsari (2015) investigated the effect of social capital on employee creativity. They employed the survey design using a convenient sample of 115 respondents. Data were elicited from the respondents using a questionnaire. Social capital and social identity were found to significantly impact on employee creativity. In view of the foregoing, we hypothesize that:

$\mathrm{H}_{0}$ 3: There is no significant relationship between social capital (collaborative work teams, employees' freedom in taking initiatives and norms of actively sharing ideas) and creativity.

\subsection{Personality traits and creativity}

Prabhu et al. (2008) investigated creativity and personality traits using intrinsic motivation as a mediating variable. They tested the effect of intrinsic and extrinsic motivation, respectively, on three personality traits (openness to experience, self-efficacy, and perseverance) and how they influence creativity. Results showed that motivation mediates the relationship between creativity and openness to experience while intrinsic motivation partially mediates this relationship. Abdullah et al. (2016) review literature on personality, creativity and innovative behaviour. They sought to enhance the etymology of personality, innovative behaviour and creativity. Based on extensive literature, they came up with the accepted framework named as big five inventory. Given the foregoing, we hypothesize that:

$H_{0} 4$ : Personality traits do not significantly influence creativity. 


\subsection{Creativity and organisational efficiency}

Sözbilir (2018) investigated the influence of social capital on creativity and how it impacts on organisational efficiency. The survey design was employed and questionnaire was used to elicit data on respondents' perceptions of social capital, creativity and organizational efficiency from one 131 managers in the Turkish Employment Agency, Turkey. SmartPLS software was used to analyse the data. Results showed that social capital significantly influences creativity and organizational efficiency and that creativity significantly influences organizational efficiency.

Barrett et al. (2005) examined the impact of creativity on performance in non-profits. The found that sound use of creativity can improve planning, implementation, and control by non-profit organization managers. Siddiqi and Qureshi (2016) investigated the impact of creativity on the performance of a firm. The design of the study was a survey of 70 randomly selected respondents. Questionnaire was used to elicit the desired information from the respondents. They found that creativity could stimulate organisational efficiency which could then enhance the overall performance of the organisation. Given the foregoing, the following null hypothesis was formulated:

$\mathrm{H}_{0}$ 5: There is no significant relationship between creativity and organisational efficiency.

Based on the conceptual and empirical review, a conceptual framework, with minor modification, is suggested and forms the conceptual framework of the study (see Figure 1).

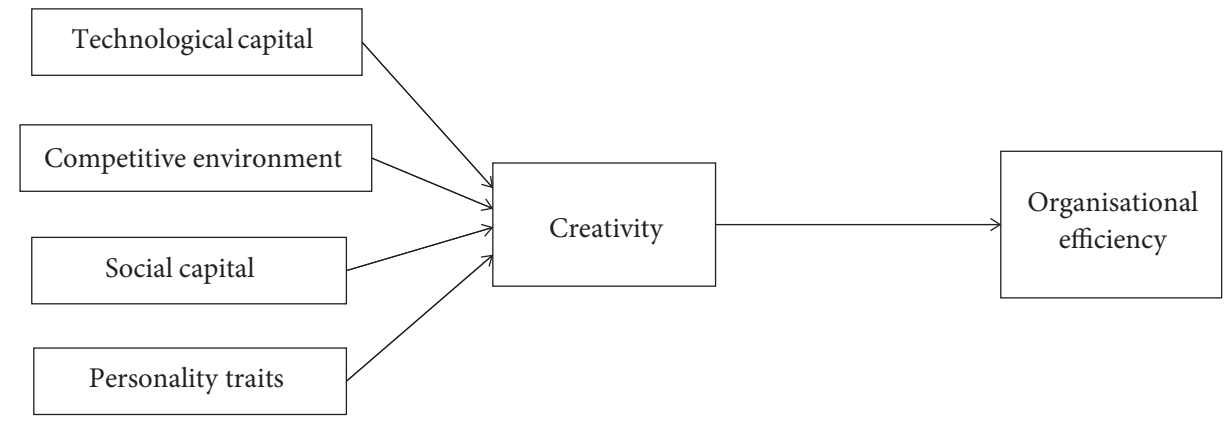

Figure 1. Conceptual framework: creativity and organisational efficiency (source: created by authors)

\subsection{Global perspective of creativity}

Shao et al. (2019) investigated how does culture shape creativity to examine how culture shapes creativity. The design of the study was a review of empirical findings across diverse studies. The results of the study revealed that impact of culture on creativity manifest through the conceptions of creativity, as well as culture (differences in creative processes and processing modes). Lubart (2010) investigated cross-cultural perspectives on creativity; culture was examined at the national level, that is, as the composite traditions, beliefs, values and preferred ways of behaving in contemporary culture. Given the vast number of national cultures globally. The study sought to find out whether the cultural dimensions of these countries 
are related to differences in creativity as well as the impact of exposure to multiple cultures on creativity. Liu and Silva (2018) investigated the dynamics of the interaction between the development of creative industries and urban spatial structure by agent-based modeling in Nanjing, China, by outputting a set of adaptive scenarios through time and space. The results reveal that the spatial distribution of both the creative firms and the creative workers is not related to urban economic condition. Boix-Domènech and Rausell-Köster (2018) examined the economic impact of the creative industry in the EU. Based on their findings, they concluded that the creative industries directly impact on employment and production as well as contribute to the technological progress and long-term development of the EU.

\subsection{Gap in literature}

Several studies have been conducted on creativity in recent times, focusing on some major predictors like technological development (World Economic Forum, 2018; Bonnardel \& Zenasni, 2010; Gangadharbatla, 2010; Müller \& Ulrich, 2013), competitive pressure (Meutia \& Ismail, 2017), social capital (Paramitha \& Indarti, 2014; Dehnavieh et al., 2010; Jamshidi \& Kenarsari, 2015; Sözbilir, 2018), and personality traits (Prabhu et al., 2008; Abdullah et al., 2016). However, only a few of the studies related creativity to organisational efficiency. Out of the studies reviewed, only Sözbilir (2018) examined the influence of creativity on organisational efficiency. Besides, the literature on creativity in Nigerian organisations is very scanty. This study sought to fill these gaps especially against the backdrop of the macroeconomic instability occasioned by political instability and declining economic fortunes in the Nigerian economy.

\section{Theoretical review}

Some models of creativity are presented below. They include the investment, creative process, metaphoric, descriptive and componential models. While there are several models of creativity, the choice of these models was informed by their perceived relevance to the study. The investment model describes some basic characteristics of creative individuals which make them to stand out. The creative process theory attempts to describe a process through which individuals are able to achieve creativity. The descriptive model, like the creative process theory, suggest four procedures through which creativity can occur, the metaphoric model presents three metaphors used to describe creativity, while the componential theory explains that the level of creativity exhibited by a person is a function of the factors operating within and around a person, thus implying that personality factors and environmental factors are critical to creativity. Thus, the theories/models were included because of the authors' perception of their succinct explanation of creative individuals. In the final analysis, the componential theory of creativity and investment theory of creativity served as the theoretical framework. These two theories were preferred to the other two because of the perceived confluence of personality factors and environmental factors that explain creative individuals since the study views creativity in the organisations from the point of view of the creative individuals in the organisations. 


\subsection{Investment model of creativity}

The investment theory of creativity is a convergent theory which regards creative people as those who are willing and able to "buy low and sell high" in the realm of ideas. Buying low means pursuing ideas that are unknown or out of favour but that have growth potential (Sternberg, 2006). When presented, these ideas usually encounter resistance at the initial stage. It is characteristic of the creative individual to persist even in the face of such resistance, no matter how stiff, and eventually sell high moving on to the next new or unpopular idea. Investment theory views creativity as consisting of convergence of six distinct but interrelated resources, which are intellectual abilities, knowledge, thinking styles, personality, motivation, and environment. The theory views levels of these resources as a function of the sources of individual differences but views the decision to use a resource as a more important source of individual differences.

\subsection{Descriptive models of creative design}

These models utilize free association thinking or forced associations. Rosenman and Gero (1996) suggest four procedures by which creative design might occur: combination, mutation, analogy and first principles.

The combination procedure is the process of combining features from existing designs into a new combination or configuration. Mutation involves modifying the form of some particular feature, or features, of an existing design. On the other hand, analogy consists of comparing a creative design to something. An analogy is a process of visualizing what is to be created. It allows the creator to imagine how the product is going to look like and how it is going to add value different from existing products. A first principle is a basic, foundational proposition or assumption that cannot be deduced from any other proposition or assumption. To this end, creativity anchored on first principles refers to the creation of unique products that have no match in the market place. It is a path-breaking or paradigm shift from the conventional.

\subsection{Componential theory of creativity}

The componential theory of creativity (Amabile, 1983) has two important assumptions. First,

"there is a continuum from low, ordinary levels of creativity found in everyday life, to the highest levels of creativity found in historically significant inventions; the second related underlying assumption is that there are degrees of creativity in the work of any single individual, even within one domain" (Amabile, 2012, p. 2).

The componential theory sees creativity as the production of novel and appropriate ideas to some goals. It identifies domain relevant skills, creativity-relevant processes, and intrinsic task motivation, which are within the individual as well as the social environment where the individual works, which is outside the individual, as the relevant factors to any creative process. The modified version of the theory includes organizational creativity and innovation and its implications for the work environments. 


\subsection{Theoretical framework}

This study's perception of creative individuals is from the point of view of Amabile's (2012) componential theory of creativity and Sternberg's (Sternberg \& Lubart, 1991) investment theory of creativity. This is because of the perceived confluence of personality factors (intrinsic motivation) and environmental factors (technology, competitive environment and social capital) contained in the two theories which are consistent with the problem of the study. Thus, the theoretical framework of the study consists of Amabile's (2012) theory of creativity and Sternberg's (Sternberg \& Lubart, 1991) investment theory of creativity.

\section{Methodology}

\subsection{Participants}

Two hundred and twenty-five employees from 10 multinational organizations in Nigeria (The Coca-Cola Company, Mobil, Nestlé, Cadbury, Julius Berger, Seven-Up Bottling Company Ltd, MTN Group, Guinness Nigeria, PZ Cussons Nigeria Plc and Unilever Nigeria Plc) ranging in age from 29 to 50 years old (134 men and 91 women), out of four hundred that were requested, voluntarily participated in the study. These participants were randomly selected from members of the Master of Business Administration (MBA) alumni of the University of Benin (UNIBEN), Nigeria. The choice of these companies was informed by the perception that they require constant creative and innovative measures to remain competitive in their respective industries. Specifically, samples were taken from the MBA alumni of UNIBEN who graduated between the year 2003 and 2014. The sample consisted of full-time and parttime graduates. The participation of respondents in the study was requested via social media. Data were elicited from the respondents with a structured questionnaire (see Appendix 1).

\subsection{Measures}

The study adapted measurement items related to the extant literature and employed a 5-point Likert scale for all the measures. Creativity was measured by four constructs; technological capital, social capital, competition and personality. Eleven items were constructed for these constructs. Organisational efficiency was treated as a latent variable. The measured items are explained below. Some of the measures used in the study were adapted from the literature, especially Sözbilir (2018), Amabile (1983, 2012) and Sternberg (2006).

\subsubsection{Technological capital}

The researchers measured technological capital as investment in technology, state of the art equipment in the organisation and information communication technology. Cronbach's alpha, the reliability statistic, was 0.72 for this scale.

\subsubsection{Competition}

This construct was measured by the perceived aspects of competition that could influence organisational efficiency: competitors' dominance and competitors' product pricing. The reliability statistic (Cronbach's alpha) was 0.71 . 


\subsubsection{Social capital}

Three items were used to measure social capital; they are employees' level of collaboration in the organisation, freedom in taking initiative at work, and the degree to which employees share ideas freely in the organisation. The reliability statistic (Cronbach's alpha) was 0.71 .

\subsubsection{Personality traits}

Personality related characteristics of individuals were measured by level of education; intellectual knowledge, and need for achievement. The reliability statistic (Cronbach's alpha) was approximately 0.70 to one significant figure.

\subsection{The model}

$$
\begin{gathered}
\mathrm{CR}=\mathrm{f}(\mathrm{TC}, \mathrm{CP}, \mathrm{SC}, \text { and PT }) \\
\mathrm{CR}=\beta_{0}+\beta_{1} \mathrm{TC}+\beta_{2} \mathrm{CP}+\beta_{3} \mathrm{SC}+\beta_{4} \mathrm{PT},
\end{gathered}
$$

where: $\mathrm{CR}=$ Creativity; $\mathrm{ORGE}=$ Organisational efficiency; $\mathrm{TC}=$ Technological capital; $\mathrm{CP}=$ Competition; SC = Social capital, and PTs = Personality traits.

Important: $\beta_{0}=$ proportion of the variation in creativity that is not explained by variations in the explanatory variables (SPC, CP, SC and PTs) and $\beta_{1}, \beta_{2}, \beta_{3}$ and $\beta_{4}$ are the slopes of SCP, CP, SC and PTs respectively.

\subsubsection{Data analysis}

SEM was performed to examine the relationship between the explanatory variables (technological capital, competition, social capital, technological capital, as personality) and creativity on one hand, as well as the relationship between creativity, personality and organizational efficiency on the other hand. Creativity (L1) and organizational efficiency (L2) were treated as latent variables while creativity constructs; technological capital, competition, social capital and personality traits were measured by the respondents' perceptions. The SEM is given by:

$$
\text { SEM (TC, CP, SC, and PTs <-L1) }(\mathrm{L} 1<-\mathrm{L} 2) \text {. }
$$

\section{Results}

The results of the goodness of fit test of the SEM of creativity and the constructs had a calculated chi-square value of 7.259 with an associated significant probability of 0.067 . The implication is that the null hypothesis that the model is a good fit cannot be rejected at $5 \%$ level of significance (see Table 1).

Table 1. Goodness of fit - creativity constructs and creativity (source: created by authors)

\begin{tabular}{c|l} 
Fit statistic & Value description \\
Likelihood ratio & \\
chi2_ms(5) & $\begin{array}{l}7.259 \text { model versus } \text { saturated } \\
\text { p }>\text { chi2 }\end{array}$ \\
chi2_bs(10) & $\begin{array}{l}8.067 \\
\text { p }>\text { chi2 }\end{array}$ \\
\end{tabular}


In the same vein, the goodness of fit test of organisational efficiency and creativity constructs had a calculated chi-square of 9.04 and an asymptotic significant probability of 0.059 , thus indicating that the model is a good fit (see Table 2).

Table 2. Goodness of fit - creativity constructs and organisational efficiency (source: created by authors)

\begin{tabular}{c|l} 
Fit statistic | Value description \\
\hline Likelihood ratio & \\
chi2_ms(5) & $\begin{array}{l}9.04 \text { model versus saturated } \\
\text { p }>\text { chi2 }\end{array}$ \\
$\begin{array}{c}0.059 \\
\text { chi2_bs(10) }\end{array}$ & $\begin{array}{l}9.82 \text { baseline versus saturated } \\
\text { p chi2 }\end{array}$ \\
\end{tabular}

The structural equation model for creativity constructs versus creativity indicates that the creativity constructs (competition, social capital and technological capital) are good predictors of creativity (L1) since the calculated z-score and associated asymptotic significant probabilities of the constructs are: 2.17 (0.031), 2.84 (0.0023), $1.83(0.047)$ and $-0.78(0.101)$ for competition, social capital, technological capital and personality respectively (see Table 3 ), thus indicating that competition and technological capital are significant at $95 \%$ confidence level while social capital is significant at the $99 \%$ confidence level but personality was not significant.

Table 3. Constructs of creativity and creativity (source: created by authors)

\begin{tabular}{|l|c|c|c|c|c|}
\hline \multicolumn{1}{|c|}{ (Latent) } & Measured path & Coefficient & z-score & $p$-value & Results \\
\hline Creativity (L1) & $\mathrm{CP}^{*}$ & 0.26 & 2.17 & 0.031 & significant \\
\hline Creativity (L1) & $\mathrm{SC}^{*}$ & 0.27 & 2.84 & 0.0023 & significant \\
\hline Creativity (L1) & $\mathrm{TC}^{*}$ & 0.54 & 1.83 & 0.047 & significant \\
\hline Creativity (L1) & $\mathrm{PTs}^{*}$ & -0.09 & -0.78 & 0.101 & not significant \\
\hline
\end{tabular}

${ }^{*}$ Note: L1 - predictor of creativity; CP - competition; SC - social capital; TC - technological capital; PTs - personality traits.

Also, the structural equations model of creativity and organisational efficiency indicates that creativity is a good predictor of organisational efficiency (L2) since the calculated z-score and associated asymptotic significant probabilities are $1.78(0.044)$, thus indicating that creativity is significant at the $95 \%$ confidence level (see Table 4 ).

Table 4. Creativity and organisational efficiency (source: created by authors)

\begin{tabular}{|c|c|c|c|c|c|}
\hline (Latent) & Measured path & Coefficient & z-score & $p$-value & Results \\
\hline $\begin{array}{l}\text { Organisational } \\
\text { Efficiency (L2) }\end{array}$ & Creativity (L1)* & 0.21 & 1.78 & 0.044 & significant \\
\hline
\end{tabular}

Lastly, Table 5 presents the F-tests (analysis of variance) of respondents' perception and demographic variables. The results show that respondents' perception is related to age, employment status and type of organisation but not related to sex, marital status and educational background. 
Table 5. Respondents' perception versus demographic variables (source: created by authors)

\begin{tabular}{|l|c|c|c|}
\hline \multicolumn{1}{|c|}{ Variable } & Calculated $F$-test & $p$-value & Results \\
\hline Age & 3.28 & 0.029 & significant \\
\hline Sex & 1.34 & 0.427 & not significant \\
\hline Marital status & 1.97 & 0.16 & not significant \\
\hline Education & 2.87 & 0.068 & not significant \\
\hline Employment status & 8.108 & $<0.001$ & significant \\
\hline Organisation & 3.13 & 0.042 & significant \\
\hline
\end{tabular}

\section{Discussion of findings}

The results of the study show that competition influences creativity and that creativity predicts organisational efficiency. This means that competitors' dominance and product pricing are critical to creative thinking in Nigerian organisations. Of course, this is understandable because any organisation that does not strategize on how to compete in the industry will be overwhelmed by competition and the best way to compete favourably is to act in a novel manner concerning product offerings at all times. To this end, entities should continuously strive to perform better than competitors in terms of the quality of their offerings and in terms of adequate pricing of their products which means minimising the cost of production. The results are partially consistent with Meutia and Ismail (2017) which showed that competitive pressure does not affect creativity skill but affects the ability to adapt to the business environment. The findings further indicate that social capital significantly influences creativity. Thus, personal interactions and networks both within and outside the organisation have significant implication on the creative thinking of an organisation's employees. The results are consistent with Sözbilir (2018), Paramitha and Indarti (2014), Dehnavieh et al. (2010) as well as Jamshidi and Kenarsari (2015).

Technological capital was also found to significantly impact on creativity. The implication is that an organisation's adequate investment in technology, state-of-the-art equipment and information and communications technology (ICT) significantly influence the employees' creativity. The results are consistent with Bonnardel and Zenasni (2010), Gangadharbatla (2010) as well as Müller and Ulrich (2013). Furthermore, the results of the study show that creativity significantly influences organisational efficiency, this means, that creative employees cay use less inputs to achieve same or more outputs and thus help to sufficiently reduce and organisation's cost of production. This is consistent with Sözbilir (2018), Barrett et al. (2005) as well as Siddiqi and Qureshi (2016) whose studies all indicate that creativity has implications for organisational efficiency. However, the findings of this study did not provide support for personality traits as personality traits were found not to have a significant impact on creativity. This is inconsistent with Prabhu et al. (2008) and Abdullah et al. (2016). Lastly, level of education, intellectual knowledge and feelings of inferiority facilitate creative thinking. While it is not strange to associate intellectual knowledge and education to creativity, it might sound strange to hear that feelings of inferiority are relevant to creativity. The truth is that a feeling of inferiority often acts as a push factor to the person or persons that feel inferior. 
The implication of the foregoing is that for an organisation to be efficient it must recruit and manage a creative workforce. Understandably, respondents' perception is related to age, employment status and type of organisation because people from different organisations have different creative climate while people in different age brackets have different attitudes towards risk-taking expected of creative individuals. Also, unemployed people may not have a practical experience of what it takes to exercise freedom or what risk-taking is all about. The results are also partly consistent with the findings of Isaksen and Akkermans (2011), Weinzimmer et al. (2011), and Stojcic et al. (2018). The point of departure of this study from most previous studies is the inclusion of competition among the key drivers of creativity having found competitive dominance to be a push factor for creativity.

\section{Proposed model}

Based on the findings, a model of creativity and organisational efficiency is proposed. The model is preceded by a model of predictors of creativity (see Figure 2). The proposed model of creativity and organisational efficiency shows that competition (competitors' dominance and product pricing), social capital (collaborative teamwork, freedom to take initiatives and actively sharing ideas), as well as Technological capital (an organisation's investment in technology, investment in state-of-the-art equipment, and an organization's ICT), stimulate creativity. Such creative thinking focuses on doing things better, especially using less inputs to produce same or more outputs; which ultimately stimulate organisational efficiency. In the final analysis, competition, social capital and technological capital stimulate creative thinking and creativity anchored by the trio of competition; social capital and technological capital positively influence organisational efficiency (see Figure 3).

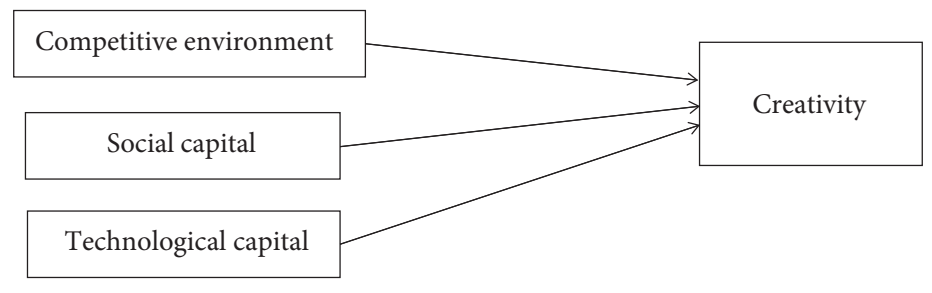

Figure 2. A proposed model of predictors of creativity (source: created by authors)

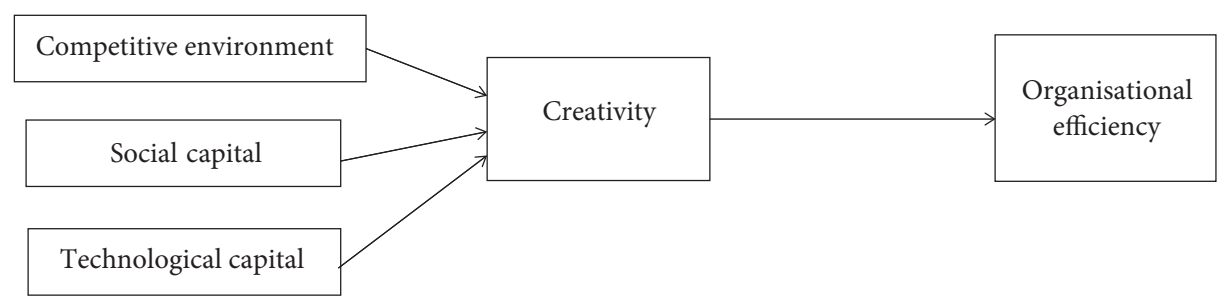

Figure 3. A proposed model of creativity and organisational efficiency (source: created by authors) 


\section{Implications for managers}

Organisational efficiency is sacrosanct to organisational competitiveness and profitability and hence, its going-concern and capacity to continually attain its set goals. But creativity stimulates organisational efficiency; to this end, strategic managers should be concerned about how best to harness the creative potentials of their employees to enhance organizational efficiency in particular and economic growth in general. Specifically, employees should be provided with the ideal creative climate by way of social capital (a form of personal interactions and networks both within and outside the organisation; which means they should be encouraged to interact and think and provided a conducive environment to think too). In view of the relevance of technological capital to creativity, management should invest in state-of-the-art technology to enable employees to be ICT compliant. This will help to ensure that employees have access to the technology required to enhance performance. Besides, management should make it a point of duty to train their employees regularly to enhance their intellectual knowledge and thus predispose them to think. In a nutshell, strategic managers should have concern creativity as part of their programme for their organisations.

\section{Conclusions}

Creative people need a supportive environment to facilitate the utilization of their creative capacities to the benefit of the organizations to which they belong. Major aspects of the environment that may prove supportive include; social capital (freedom to take initiative in the course of their duties, and collaboration in work teams), technological capital (investment in technology, state-of-the-art facilities, and ICT) as well as competition (competitive dominance and competitors' product pricing). A creative organisation will, no doubt, be efficient and this will translate to the fulfilment of the value objective of production and enhance its going concern in particular and stimulate economic growth in general.

This study has made significant contributions to knowledge; first, it provides an update of the studies on creativity, particularly as it relates to Nigeria. The inclusion of competition (competitors' dominance) among the drivers of creativity in the organization is a point of departure from most previous studies and thus constitutes a major contribution of this study to knowledge in management science and social science research. The contribution of this study is evident in the proposed model of creativity and organisational efficiency in which the trio of a competitive environment, social capital and technological capital influence creativity, which in turn significantly influences organisational efficiency. The proposed model can form the basis for a better-refined model that can be used to predict organisational efficiency in Nigeria. This makes the model a major contribution to knowledge.

The study has some limitations. In using sample estimates to predict population parameters, it is often assumed that the sample is representative of the population from which it is chosen. One way to guarantee this representativeness is to use probability sampling techniques as was done in this study. However, there is no absolute assurance that complete randomization was achieved since the employees sampled in the ten organisations were chosen because they were within the reach of the researcher and those who attended the MBA programme of the UNIBEN between the period 2003 and 2014. There are some other 
employees of the sampled organisations who were not included because they were not in the MBA programme of the UNIBEN within the period of the study. Can we assume that the perception of those respondents would not have differed from those of the sampled respondents? Besides, there is a likelihood that other employees of the sampled organisations who are not MBA graduates may differ in their perception about the items relating to the research problem. The non-significance of education to the perception of sampled respondents may not be unconnected with the homogeneity of the educational qualification of the respondents, being all MBA graduates.

Future studies should attempt to rectify this lapse through a longitudinal study coupled with the expansion of the scope of the respondents, and data triangulation, among others. The use of respondents from multinational companies may also have constrained the perception of the respondents to some extent, given the organisational culture of such companies. Future studies should attempt to blend national companies with multinational companies to investigate any possible discrepancies in respondents' opinions.

\section{Acknowledgements}

We acknowledge the management of Landmark University, Nigeria for providing the necessary funding for this study.

\section{References}

Abdullah, I., Omar, R., \& Panatik, S. A. (2016). A literature review on personality, creativity and innovative behavior. International Review of Management and Marketing, 6(1), 177-182.

Amabile, T. M. (2012). Componential theory of creativity. Harvard Business School. Working Paper 12-096. https://www.hbs.edu/ris/Publication\%20Files/12-096.pdf

Amabile, T. M. (1983). The social psychology of creativity: A componential conceptualization. Journal of Personality and Social Psychology, 45(2), 357-376. https://doi.org/10.1037/0022-3514.45.2.357

Amabile, T. M., \& Mueller, J. S. (2008). Studying creativity, its processes, and its antecedents: An exploration of the componential theory of creativity. In J. Zhou \& Ch. E. Shalley (Eds.), Handbook of organizational creativity (pp. 33-64). Lawrence Erlbaum Associates.

Aubyn, M. St., Pina, Á., Garcia, F., \& Pais, J. (2009). Economic Papers. Vol. 390. European economy: Study on the efficiency and effectiveness of public spending on tertiary education. European Commission.

Babu, R. R., Krishna, M. M., \& Swathi, A. (2013). Role of creativity and innovation in entrepreneurship. Innovative Journal of Business Management, 2(5), 112-115.

Barrett, H., Balloun, J. L., \& Weinstein, A. (2005). The impact of creativity on performance in nonprofits. International Journal of Non-Profit and Voluntary Sector Marketing, 10(4), 213-223. https://doi.org/10.1002/nvsm.25

Bessant, J., Lamming, R., Noke, H., \& Phillips, W. (2005). Managing innovation beyond the steady state. Technovation, 25(12), 1366-1376. https://doi.org/10.1016/j.technovation.2005.04.007

Boix-Domènech, R., \& Rausell-Köster, P. (2018). The economic impact of the creative industry in the European Union. In V. Santamarina-Campos \& M. Segarra-Oña (Eds.), Drones and the creative industry: Innovative strategies for European SMEs (pp. 19-36). Springer.

https://doi.org/10.1007/978-3-319-95261-1_2 
Bonnardel, N., \& Zenasni, F. (2010). The impact of technology on creativity in design: An enhancement? Creativity and Innovation Management, 19(2), 180-191.

https://doi.org/10.1111/j.1467-8691.2010.00560.x

Damanpour, F. (1991). Organizational innovation: A meta-analysis of effects of determinants and moderators. The Academy of Management Journal, 34(3), 555-590. https://doi.org/10.5465/256406

Dehnavieh, R., Hasanzadeh, E., Mehralhasani, M. H., Pour, H. I., Shahheidari, M., \& Hekmat, S. N. (2010). Factors influencing creativity and innovation of the senior managers of Iran university of medical sciences - 2010. Research Journal of Biological Sciences, 5(11), 708-712. https://doi.org/10.3923/rjbsci.2010.708.712

Farrell, M. J. (1957). The measurement of productive efficiency. Journal of the Royal Statistical Society: Series A (General), 120(3), 253-290. https://doi.org/10.2307/2343100

Gangadharbatla, H. (2010). Technology component: A modified systems approach to creative thought. Creativity Research Journal, 22(2), 219-227. https://doi.org/10.1080/10400419.2010.481539

George, B. (2007). Authentic leaders: They inspire and empower others. Leadership Excellence, 24(9), 16-17.

Gupta, A. K. (2013). Tapping the entrepreneurial potential of grassroots innovation. Stanford Social Innovation Review. https://ssir.org/articles/entry/tapping_the_entrepreneurial_potential_of_grassroots_innovation\#

Isaksen, S. G., \& Akkermans, H. J. (2011). Creative climate: A leadership lever for innovation. Journal of Creative Behavior, 45(3), 161-187. https://doi.org/10.1002/j.2162-6057.2011.tb01425.x

James, K., \& Drown, D. (2012). Organizations and creativity: Trends in research, status of education and practice, agenda for the future. In M. D. Mumford (Ed.), Handbook of organizational creativity (pp. 17-38). Elsevier. https://doi.org/10.1016/B978-0-12-374714-3.00002-1

Jamshidi, M. H. M., \& Kenarsari, N. H. (2015). The effect of social capital on creativity of employees. A case study: Productive firms of electrical household appliances in the North of Iran. Journal of Asian Scientific Research, 5(4), 205-218. https://doi.org/10.18488/journal.2/2015.5.4/2.4.205.218

Kash, D. E. (1989). Perpetual innovation: The new world of competition. Basic Books.

Liu, H., \& Silva, E. (2018). Examining the dynamics of the interaction between the development of creative industries and urban spatial structure by agent-based modelling: A case study of Nanjing, China. Urban Studies, 55(5), 1013-1032. https://doi.org/10.1177/0042098016686493

Lubart, T. (2010). Cross-cultural perspectives on creativity. In J. C. Kaufman \& R. J. Sternberg (Eds.), The Cambridge handbook of creativity (pp. 265-278). Cambridge University Press. https://doi.org/10.1017/CBO9780511763205.017

Mansur, Y. (2015, 27-29 April). Creativity, innovation, and development. Creativity and Culture for Development: Med Culture 1st Regional Conference. Casablanca, Morocco. https://fdocuments.net/ reader/full/creativity-innovation-and-development-by-yusuf-mansur-by-yusuf-mansur

Meutia, M., \& Ismail, T. (2017). The influence of competitive pressure on innovative creativity. Electronic Business Journal, 16(11), 22-32.

Mihaiu, D. M., Opreana, A., \& Cristescu, M. P. (2010). Efficiency, effectiveness and performance of the public sector. Romanian Journal of Economic Forecasting, 4, 132-147.

Mumford, M. D., Hester, K. S., Robledo, I. C., Peterson, D. R., Day, E. A., Hougen, D. F., \& Barrett, J. D. (2012). Mental models and creative problem-solving: The relationship of objective and subjective model attributes. Creativity Research Journal, 24(4), 311-330. https://doi.org/10.1080/10400419.2012.730008

Müller, S. D., \& Ulrich, F. (2013). Creativity and information systems in a hypercompetitive environment: A literature review. Communications of the Association for Information Systems, 32, 175-200. https://doi.org/10.17705/1CAIS.03207

Oldham, G. R., \& Cummings, A. (1996). Employee creativity: Personal and contextual factors at work. The Academy of Management Journal, 39(3), 607-634. https://doi.org/10.5465/256657 
Oluwadare, A. A. (2015). Creativity and innovation: A viable tool for entrepreneurial development. Global Advanced Research Journal of Educational Research and Review, 4(11), 225-231.

Paramitha, A., \& Indarti, N. (2014). Impact of the environment support on creativity: Assessing the mediating role of intrinsic motivation. Procedia - Social and Behavioral Sciences, 115, 102-114. https://doi.org/10.1016/j.sbspro.2014.02.419

Porter, M. E., Ketels, Ch., \& Delgado, M. (2007). The microeconomic foundations of prosperity: Funding from the business competitiveness index. In M. E. Porter, X. Sala-i-Martín, \& K. Schwab, The Global Competitiveness Report 2007-2008 (pp. 51-81). World Economic Forum.

Prabhu, V., Sutton, Ch., \& Sauser, W. (2008). Creativity and certain personality traits: Understanding the mediating effect of intrinsic motivation. Creativity Research Journal, 20(1), 53-66. https://doi.org/10.1080/10400410701841955

Rhodes, M. (1961). An analysis of creativity. The Phi Delta Kappan, 42(7), 305-310.

Rosenman, M. A., \& Gero, J. S. (1996). Modelling multiple views of design objects in a collaborative CAD environment. Computer-Aided Design, 28(3), 193-205. https://doi.org/10.1016/0010-4485(96)86822-9

Serrat, O. (2009). Harnessing creativity and innovation in the workplace. Knowledge Solutions, 61. https://www.adb.org/sites/default/files/publication/27596/harnessing-creativity-and-innovationworkplace.pdf

Shao, Y., Zhang, Ch., Zhou, J., Gu, T., \& Yuan, Y. (2019). How does culture shape creativity? A minireview. Frontiers in Psychology, 10. https://doi.org/10.3389/fpsyg.2019.01219

Siddiqi, H., \& Qureshi, M. (2016). The impact of employees' creativity on the performance of the firm. Research Issues in Social Sciences, 1, 1-12.

Sözbilir, F. (2018). The interaction between social capital, creativity and efficiency in organizations. Thinking Skills and Creativity, 27, 92-100. https://doi.org/10.1016/j.tsc.2017.12.006

Sternberg, R. J. (2006). The nature of creativity. Creativity Research Journal, 18(1), 87-98. https://doi.org/10.1207/s15326934crj1801_10

Sternberg, R. J., \& Lubart, T. I. (1991). An investment theory of creativity and its development. Human Development, 34(1), 1-31. https://doi.org/10.1159/000277029

Sternberg, R. J., \& Lubart, T. I. (1995). Defying the crowd: Cultivating creativity in a culture of conformity. The Free Press.

Stojcic, N., Hashi, I., \& Orlic, E. (2018). Creativity, innovation effectiveness and productive efficiency in the UK. European Journal of Innovation Management, 21(4), 564-580. https://doi.org/10.1108/EJIM-11-2017-0166

United Nations. (2008). Creative Economy. Report 2008 - the challenge of assessing the creative economy: Towards informed policy-making. UNCTAD/UNDP.

Weinzimmer, L. G., Michel, E. J., \& Franczak, J. L. (2011). Creativity and firm-level performance: The mediating effects of action orientation. Journal of Managerial Issues, 23(1), 62-82.

World Economic Forum. (2018). Creative disruption: The impact of emerging technologies on the creative economy. World Economic Forum.

Xiao Hua, T., Badara Kabia, A., \& Arkady, D. (2015). Creativity and innovation. A road map to business success and growth in Sierra Leone: From intuition to process management. Global Journal of Management and Business Research: B Economics and Commerce, 15(4). https:/globaljournals.org/ GJMBR_Volume15/1-Creativity-and-Innovation.pdf

Yampolskiy, R. V. (2013). Efficiency theory: A unifying theory for information, computation and intelligence. Journal of Discrete Mathematical Sciences and Cryptography, 16(4-5), 259-277. https://doi.org/10.1080/09720529.2013.821361

Zahra, Sh. A., \& Covin, J. G. (1994). The financial implications of fit between competitive strategy and innovation types and sources. The Journal of High Technology Management Research, 5(2), 183-211. https://doi.org/10.1016/1047-8310(94)90002-7 


\section{Appendix 1.}

Questionnaire.

Source: created by authors.

INSTRUCTION: Please mark $(\mathrm{X})$ in the box against your chosen answer.

\section{SECTION A: Biodata}

1. Age bracket: 1-20 years [ ] 21-40 years [ ] 41-60 years [ ]

2. Sex: Male [ ] Female []

3. Marital status: Married [ ] Single [ ] Divorced [ ] Widowed [ ]

4. Highest educational qualification: National Diploma [ ] National Counselor Examination [ ] Senior Secondary Certificate Examination/National Examination Council/Higher National Diploma/First degree [ ] Higher degree [ ]

5. Employment status: Employed [ ] Unemployed [ ] Student [ ]

6. Organisation: Coca-Cola Company [ ] Mobil [ ] Nestlé [ ] Cadbury [ ] Julius Berger [ ] Seven-Up Bottling Company Ltd [ ] MTN Group [ ] Guinness Nigeria [ ] PZ Cussons Nigeria Plc [ ] Unilever Nigeria Plc [ ]

SECTION B: Research problem

\begin{tabular}{|c|c|c|c|c|}
\hline 1 & 2 & 3 & 4 & 5 \\
\hline Strongly disagree & Disagree & No view & Agree & Strongly agree \\
\hline
\end{tabular}

\begin{tabular}{|l|l|}
\hline & \multicolumn{1}{|c|}{$\begin{array}{c}\text { Indicate the extent to which you agree that the following elements } \\
\text { may stimulate creativity in organisations }\end{array}$} \\
\hline 1 & $\begin{array}{l}\text { An organisation's investment in technology } \\
\text { Investment in state-of-the-art equipment }\end{array}$ \\
3 & An organization's information and communications technology \\
\hline 4 & Competitors' dominance \\
5 & Competitors' product pricing \\
\hline 6 & Collaborative work teams \\
7 & Employees' freedom in taking initiatives \\
8 & Norms of actively sharing ideas \\
\hline 9 & Level of education \\
10 & An individual's personality traits \\
11 & An individual's feelings of inferiority \\
\hline
\end{tabular}




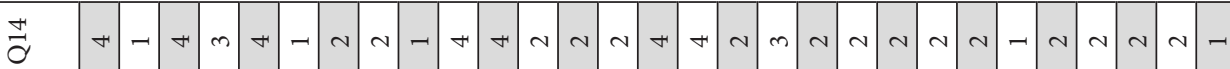

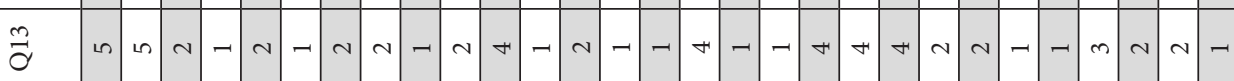

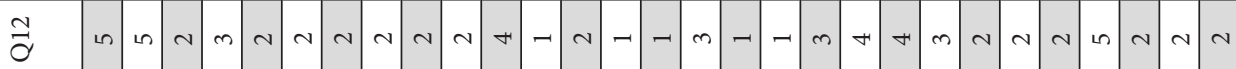

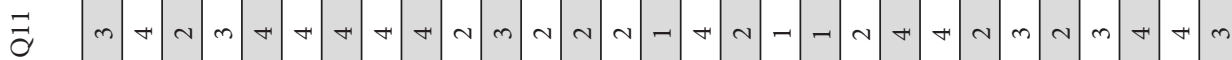

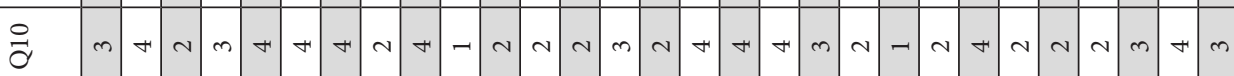

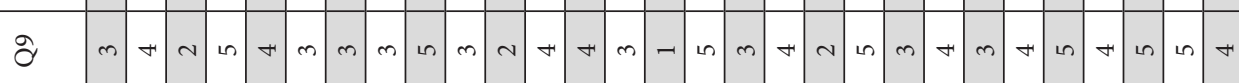

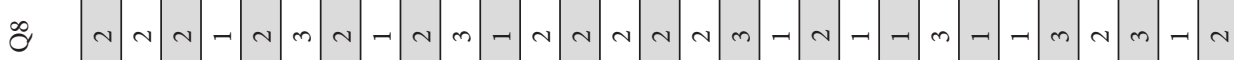

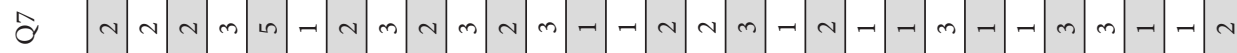

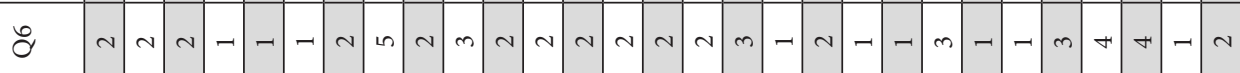

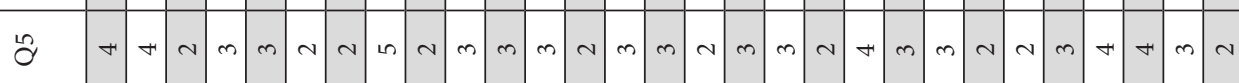

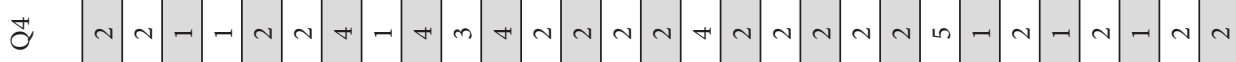

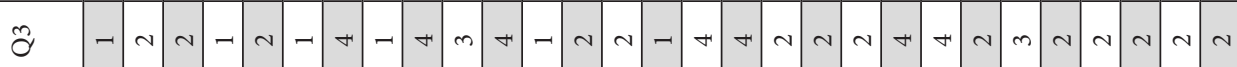

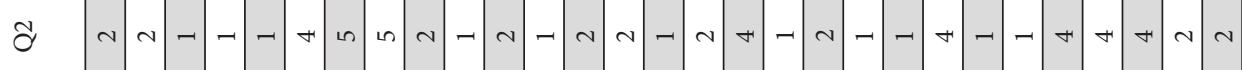

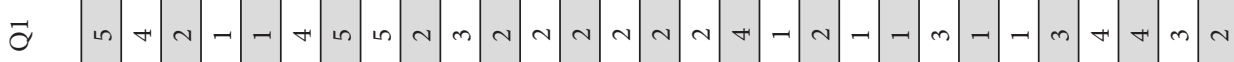

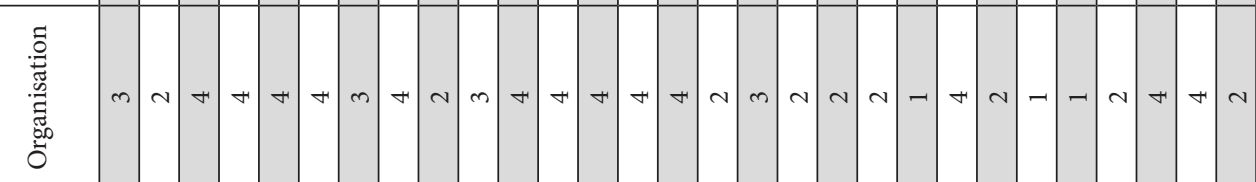

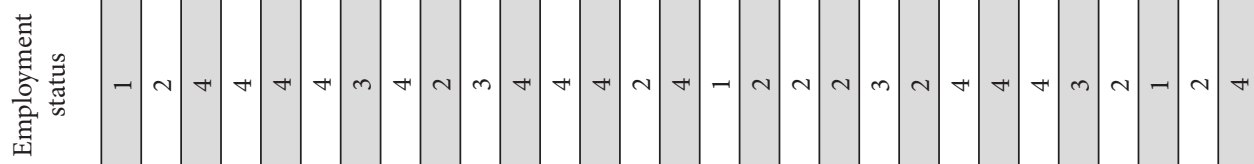

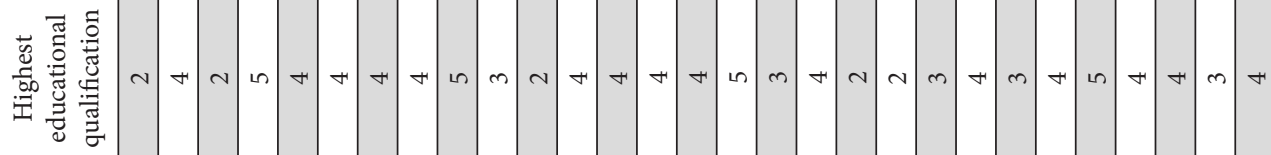

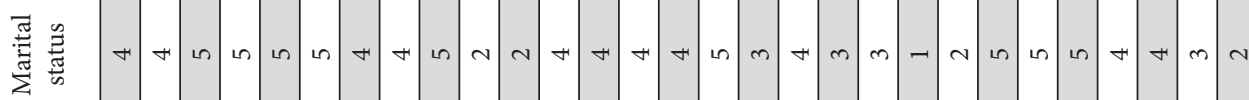

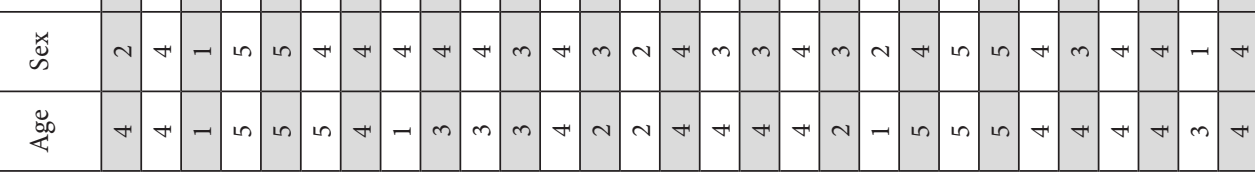




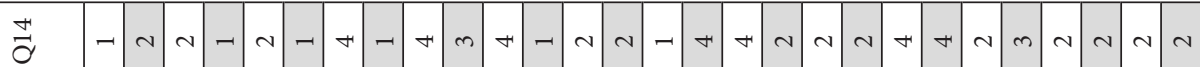

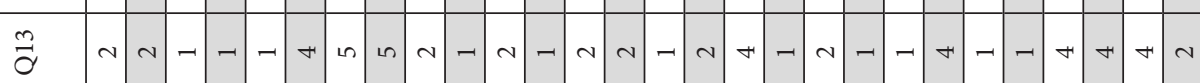

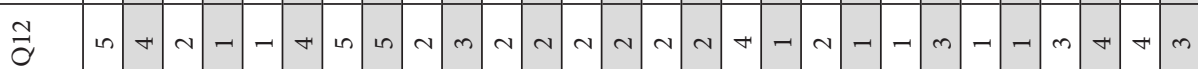

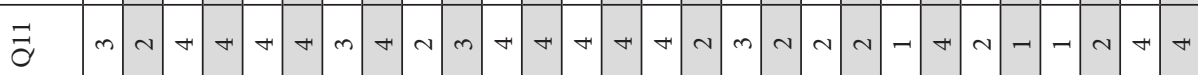

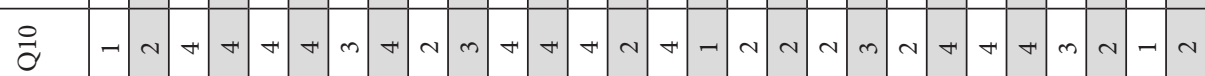

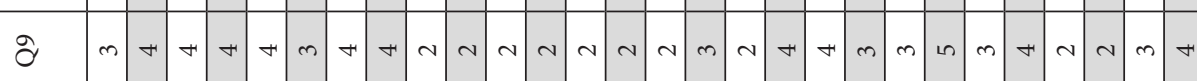

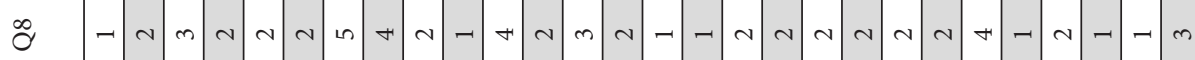

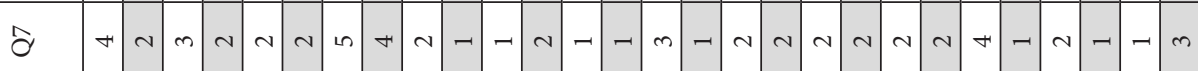

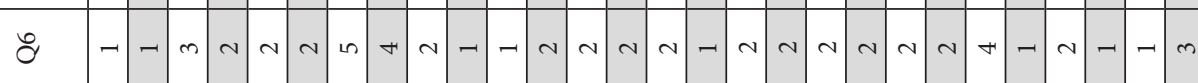

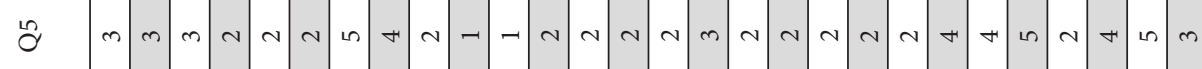

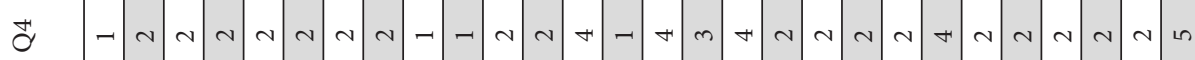

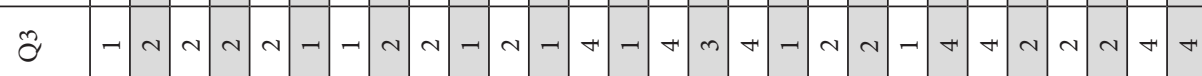

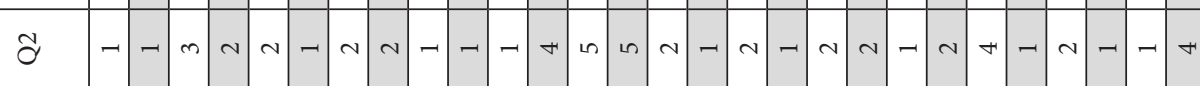

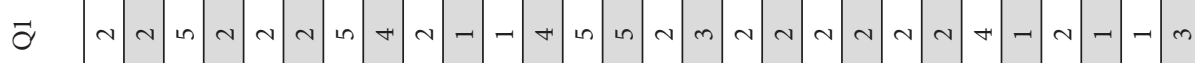

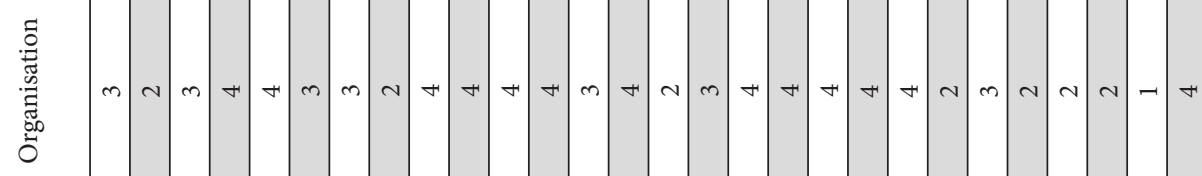

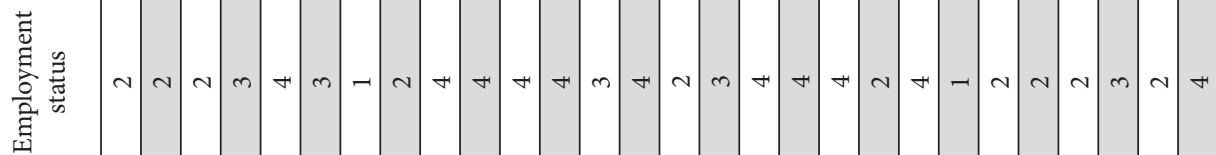

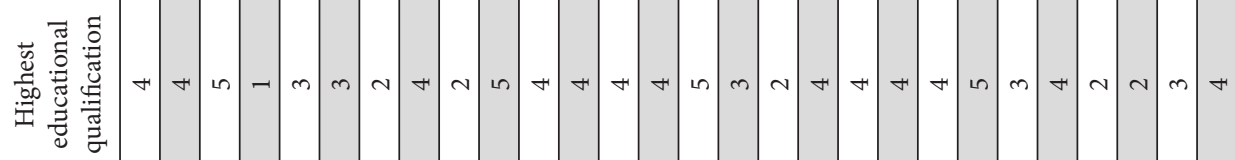

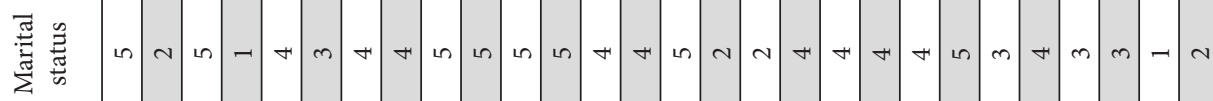

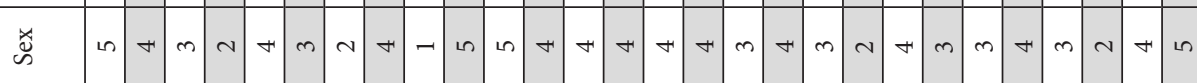

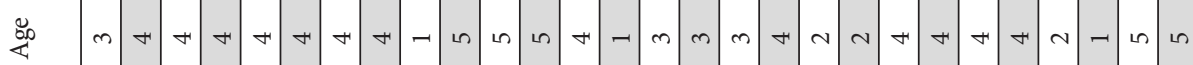




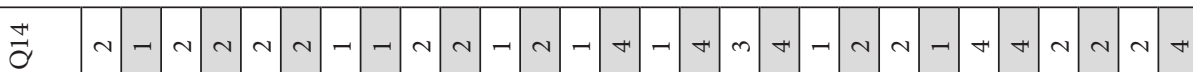

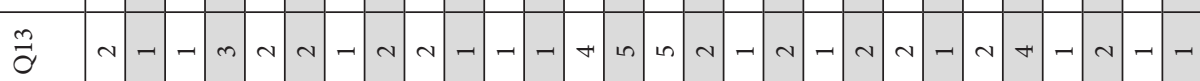

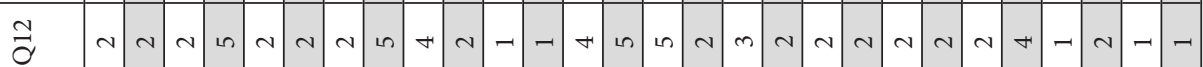

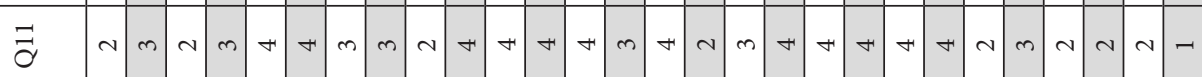

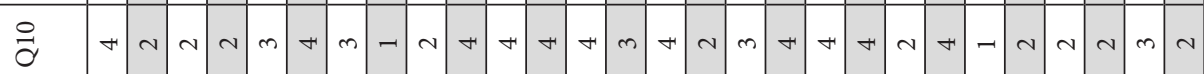

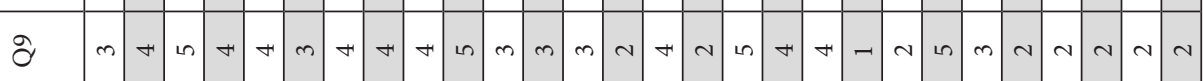

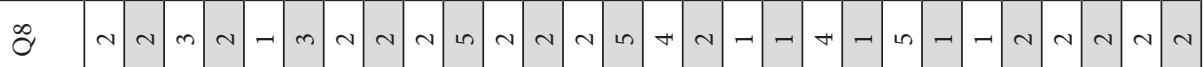

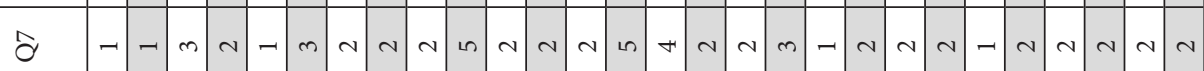

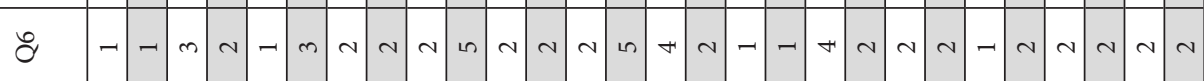

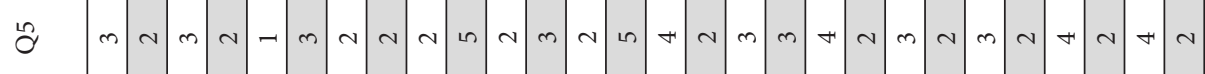

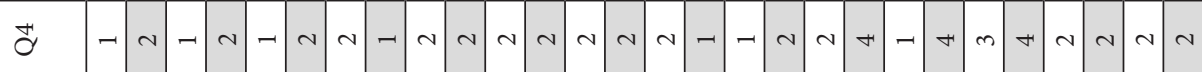

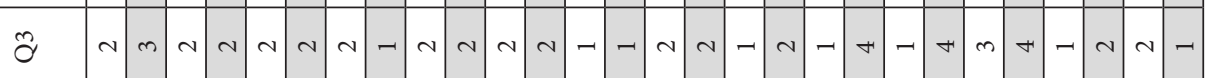

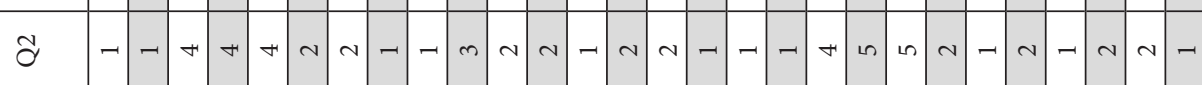

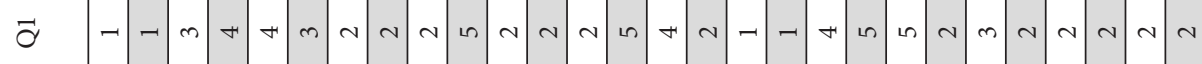

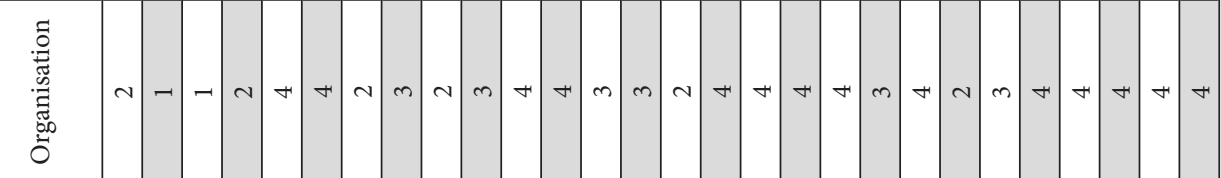

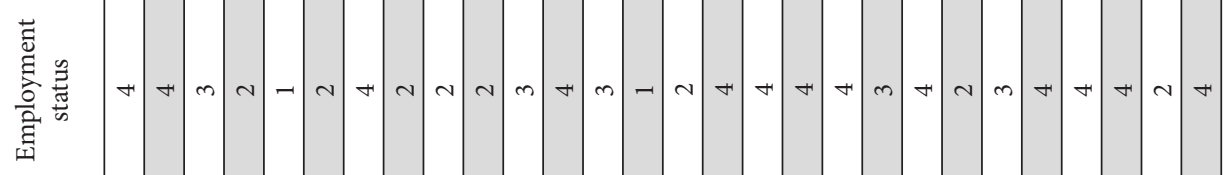

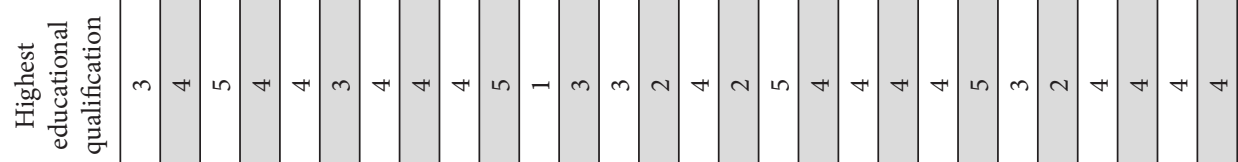

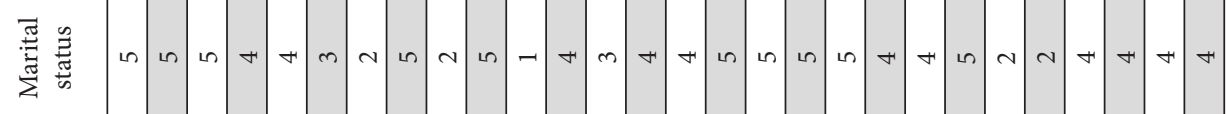

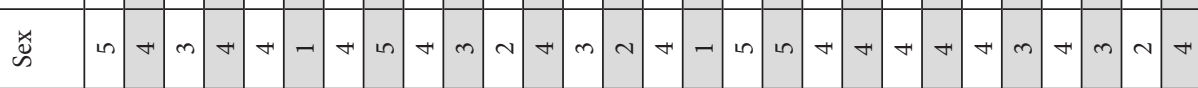

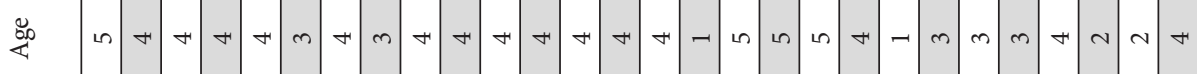




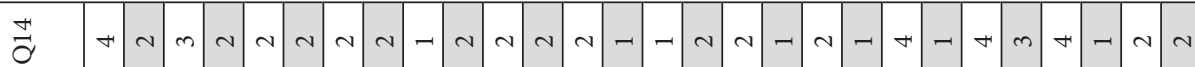

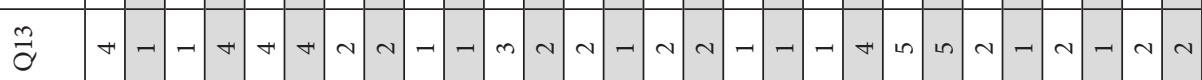

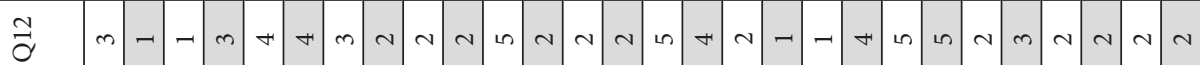

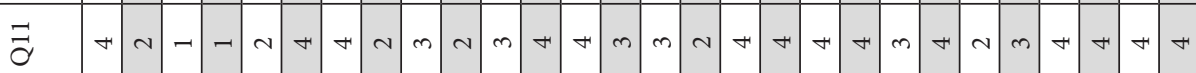

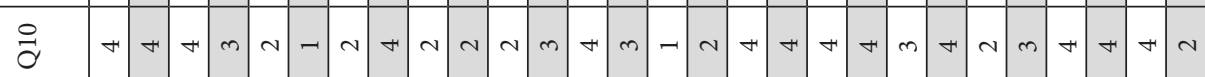

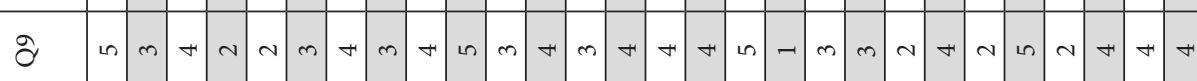

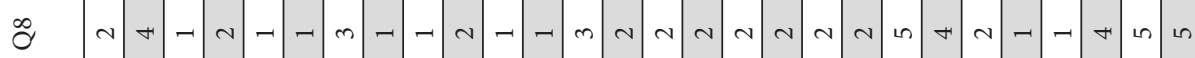

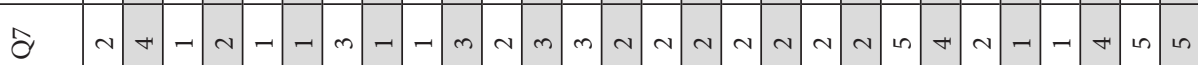

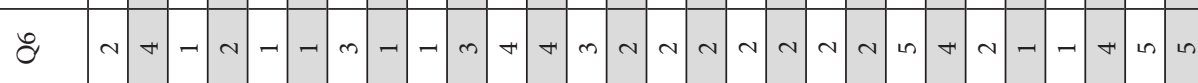

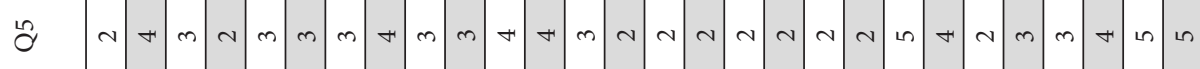

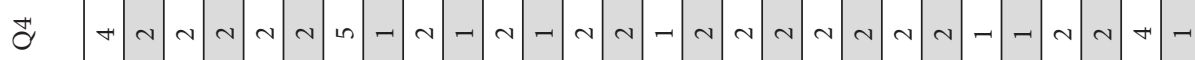

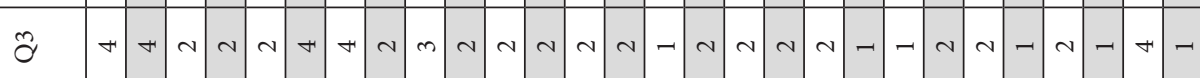

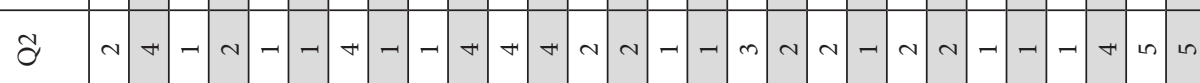

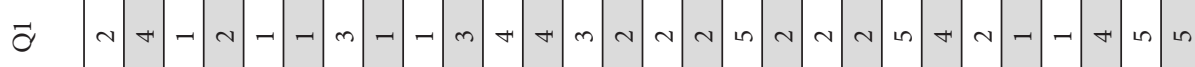

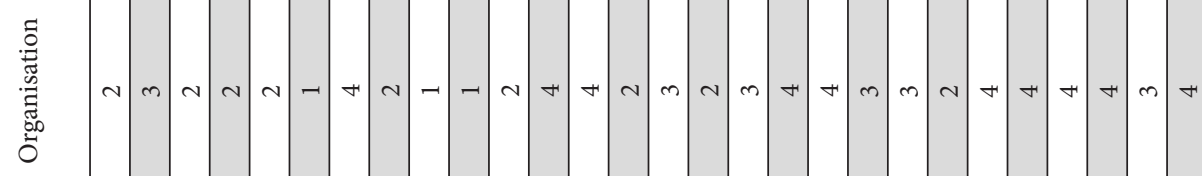

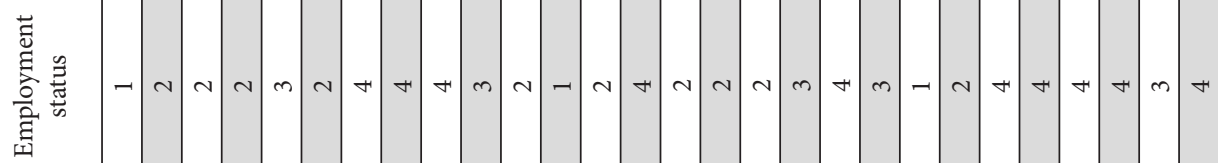

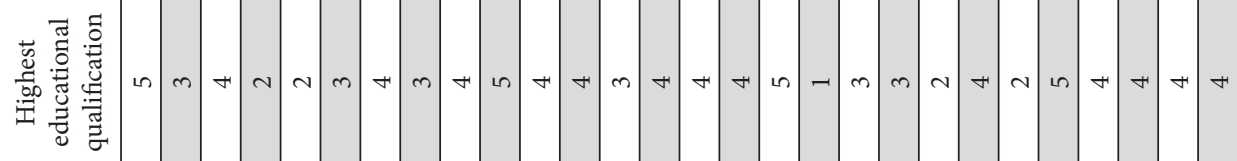

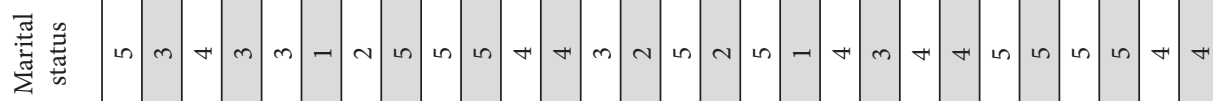

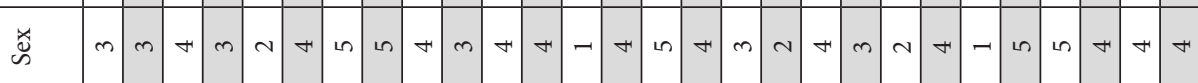

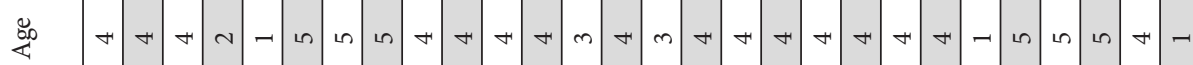




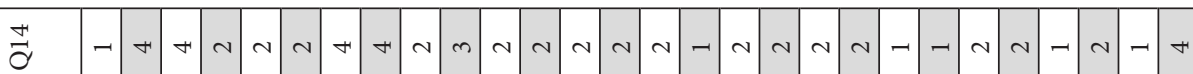

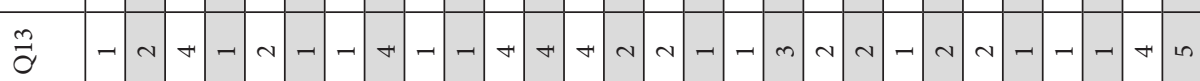

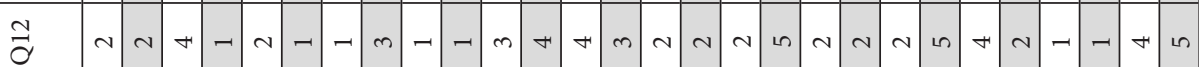

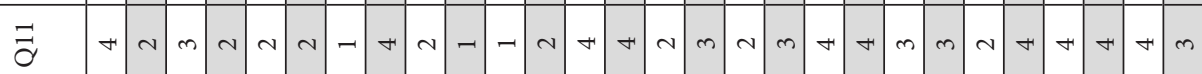

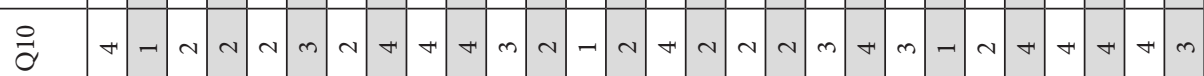

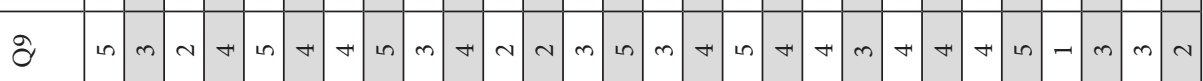

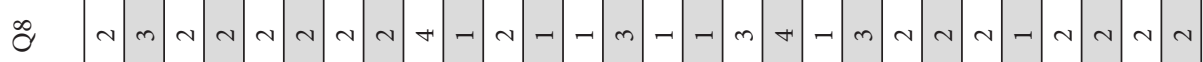

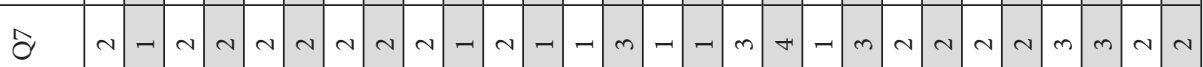

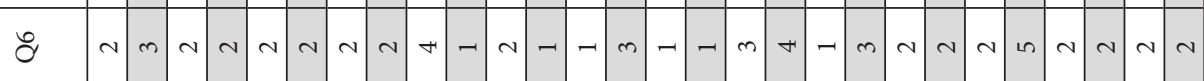

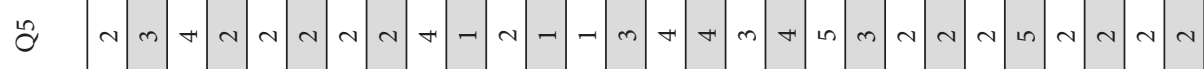

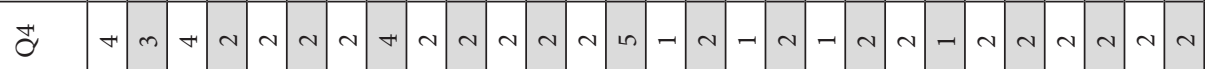

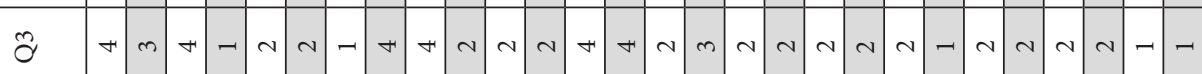

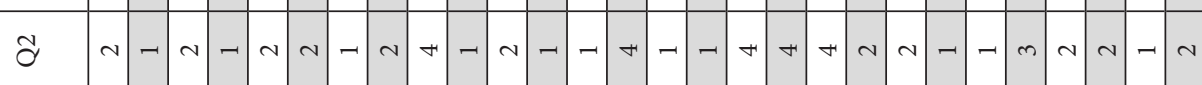

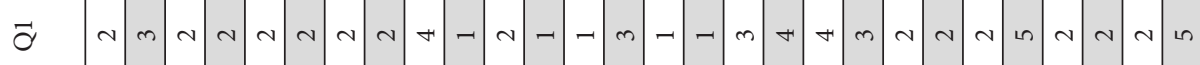

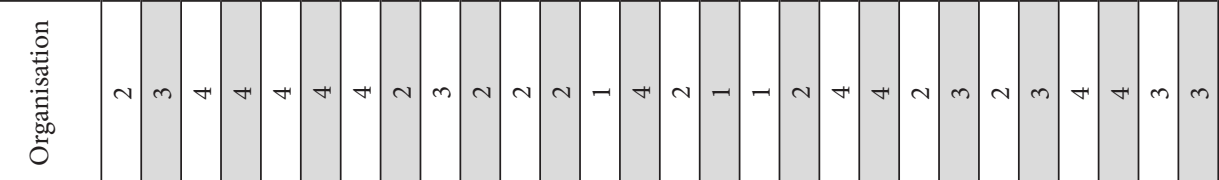

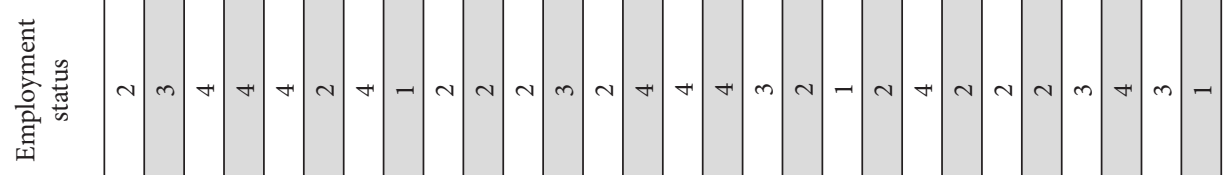

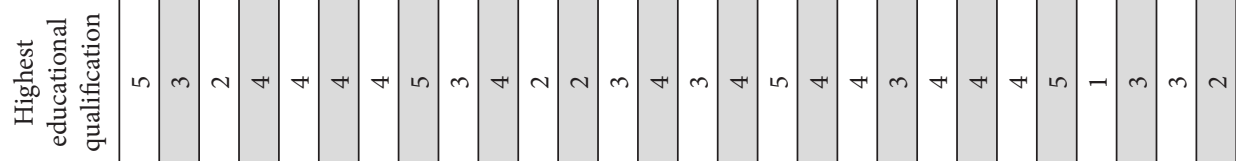

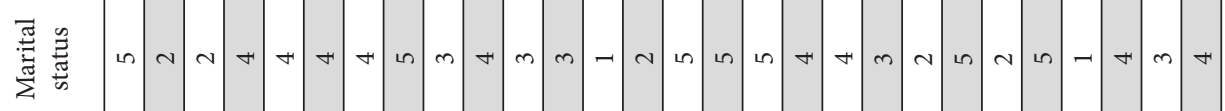

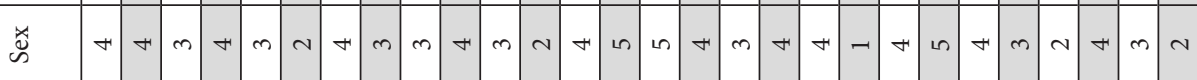

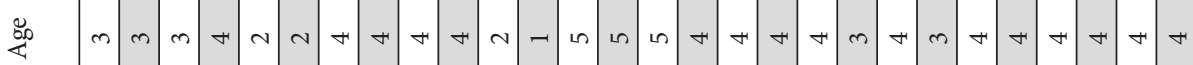




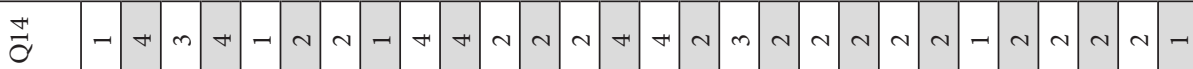

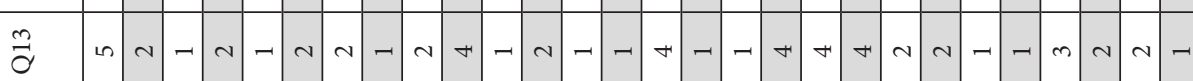

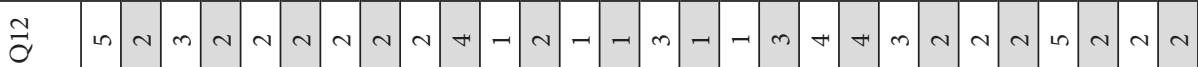

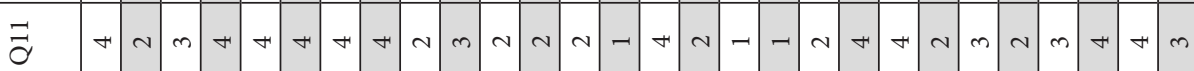

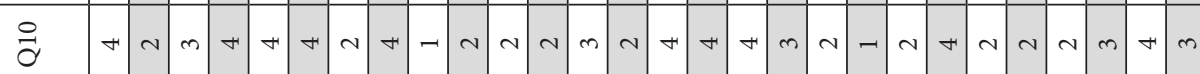

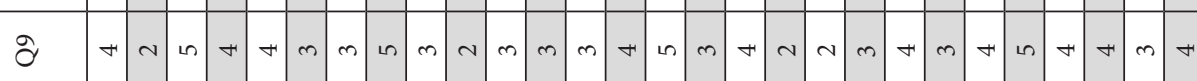

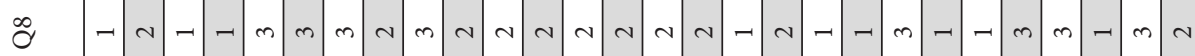

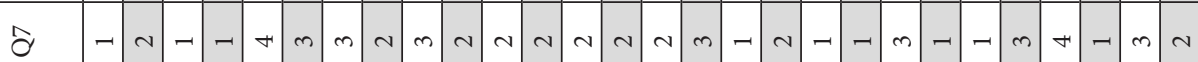

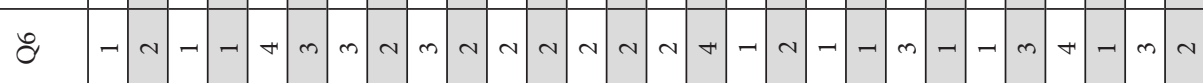

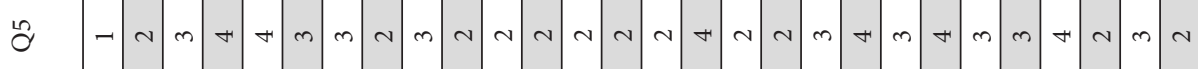

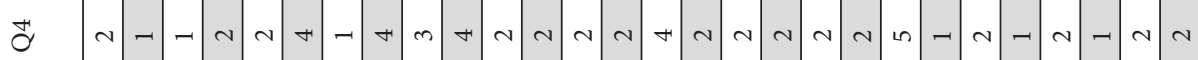

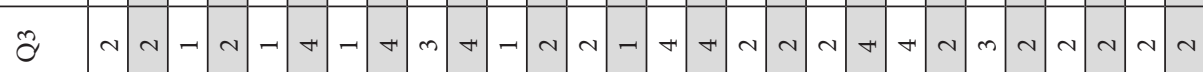

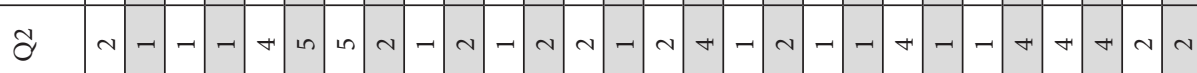

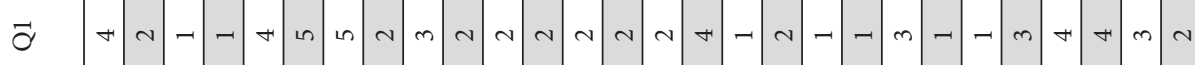

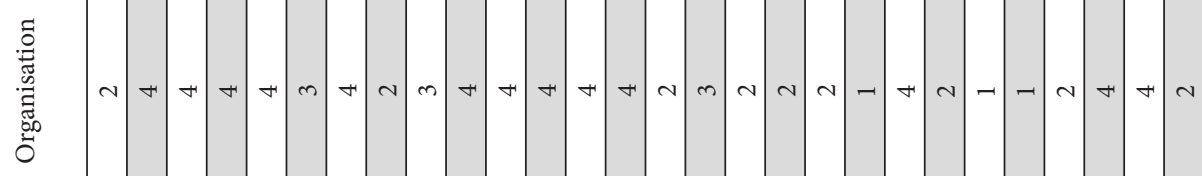

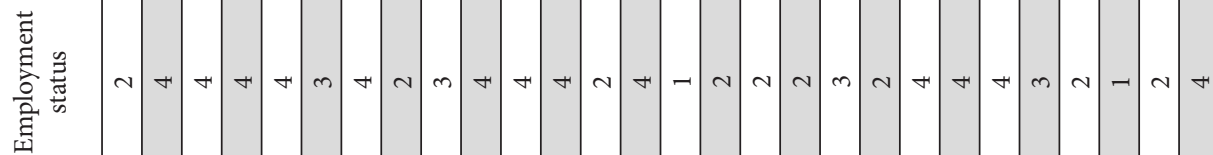

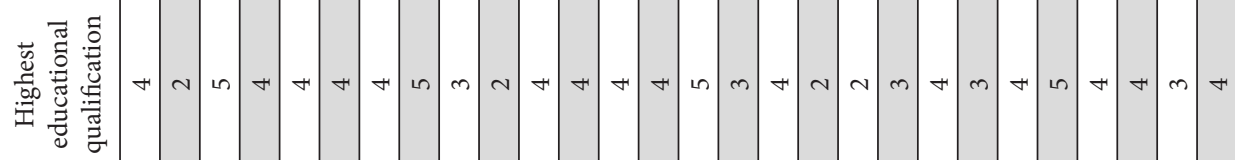

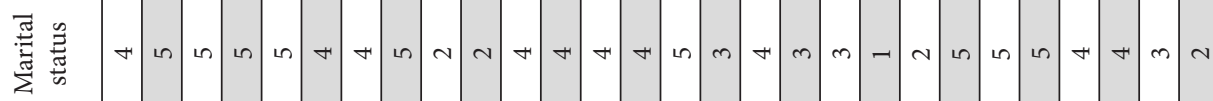

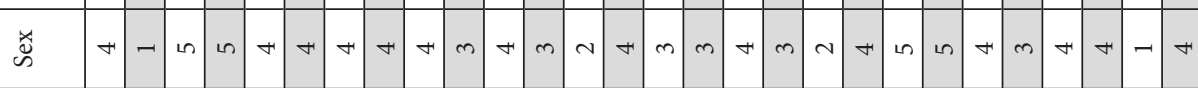

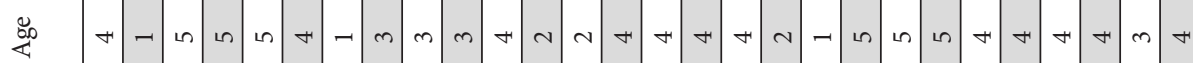




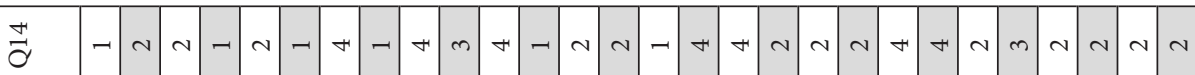

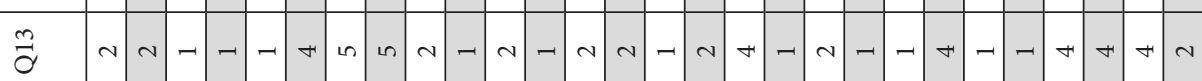

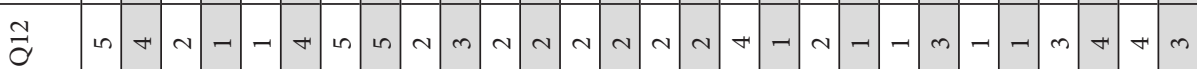

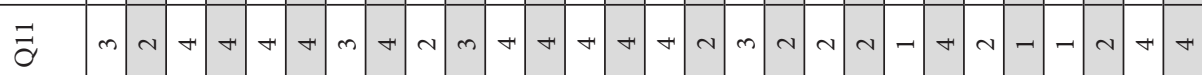

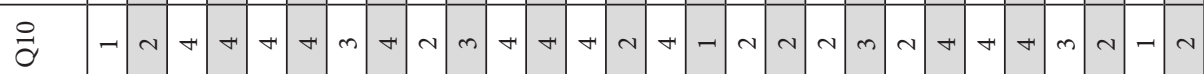

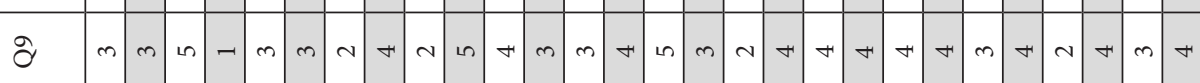

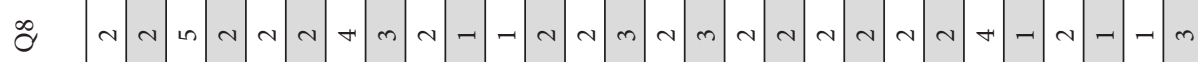

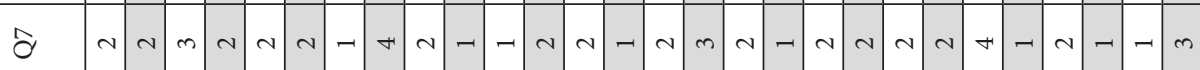

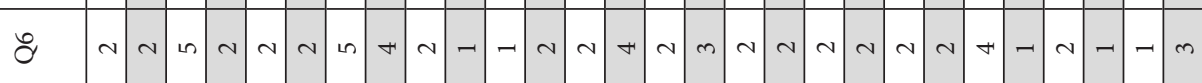

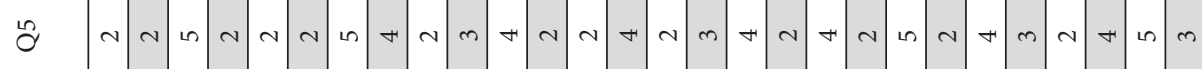

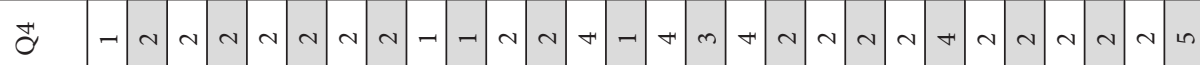

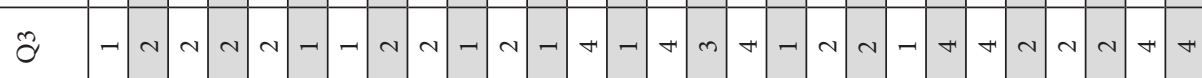

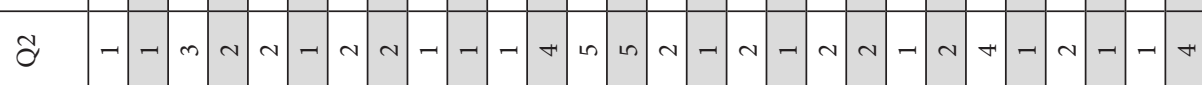

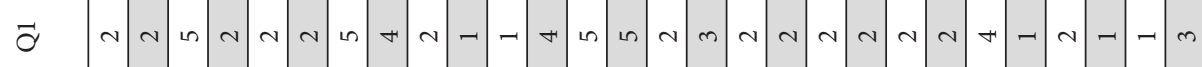

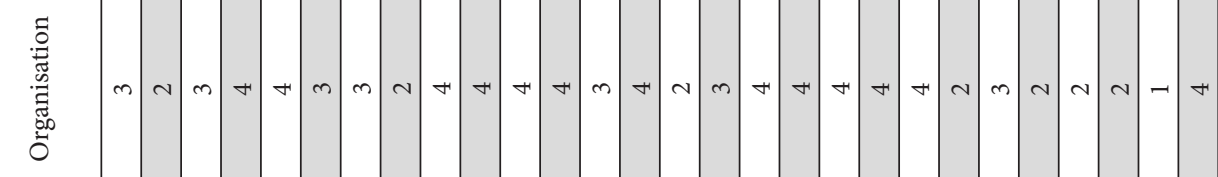

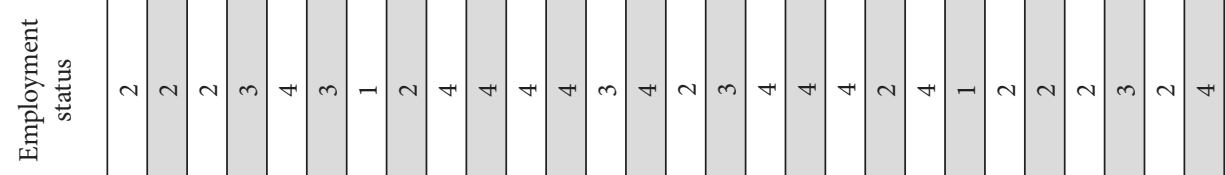

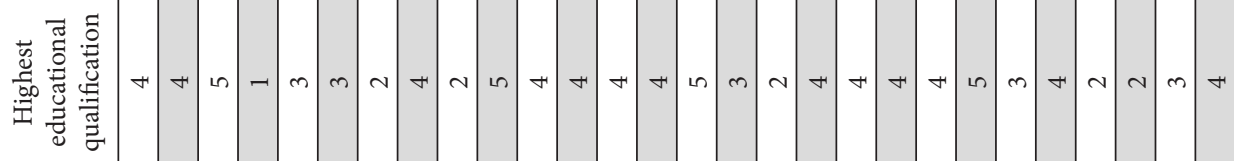

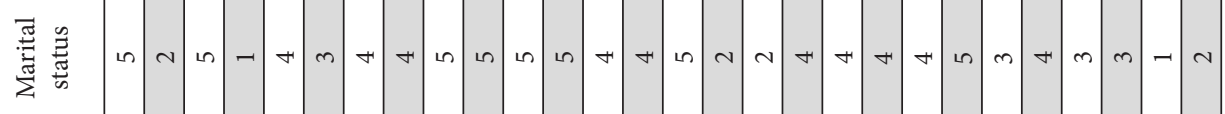

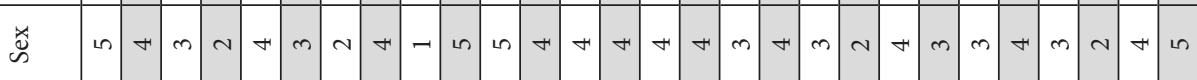

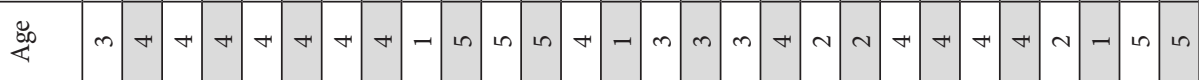




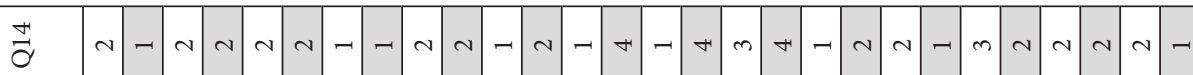

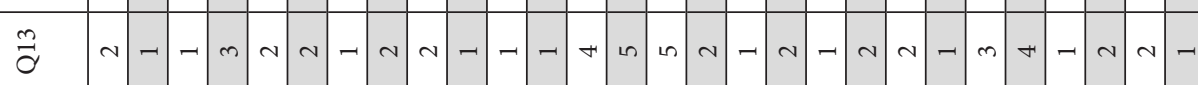

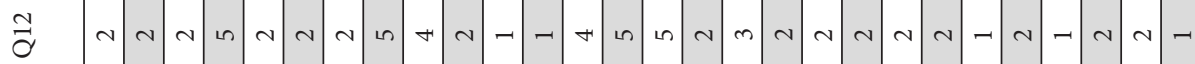

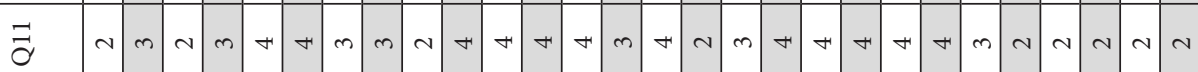

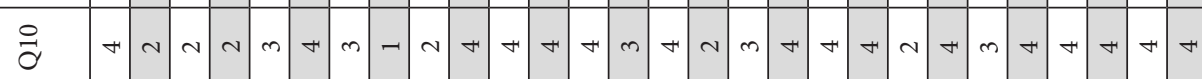

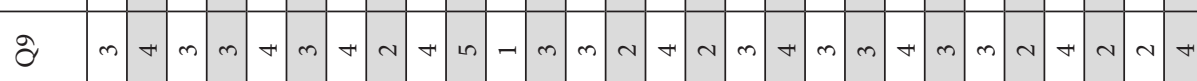

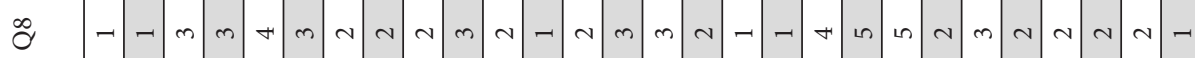

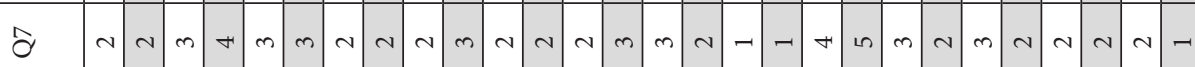

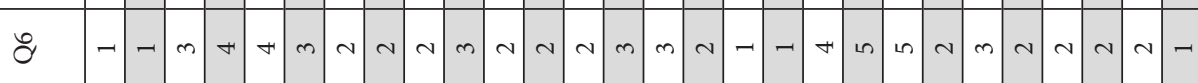

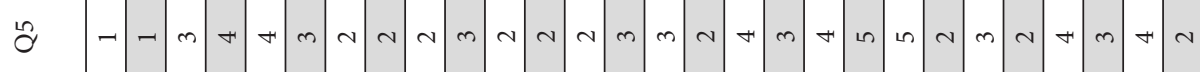

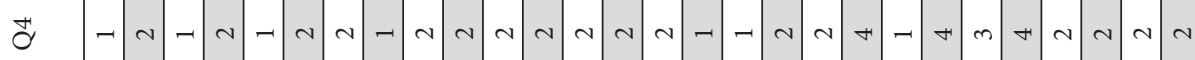

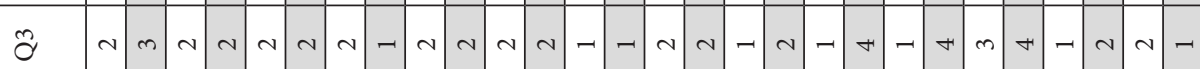

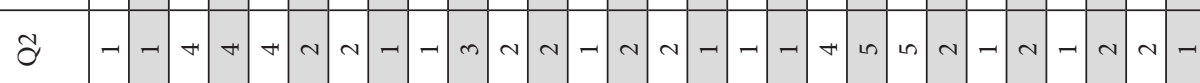

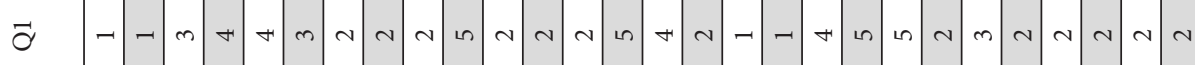

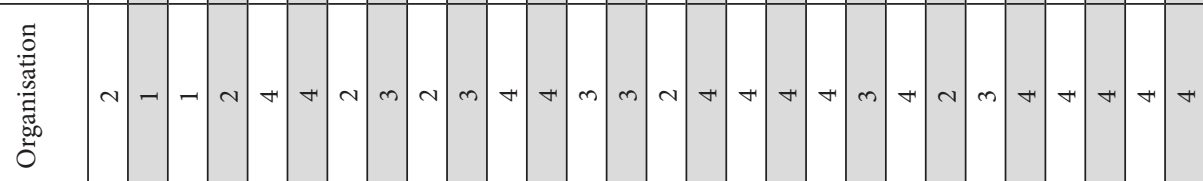

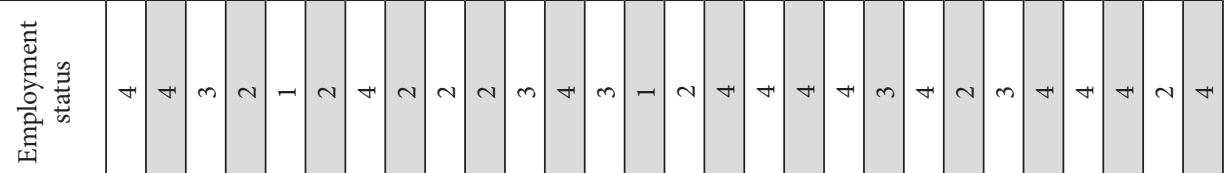

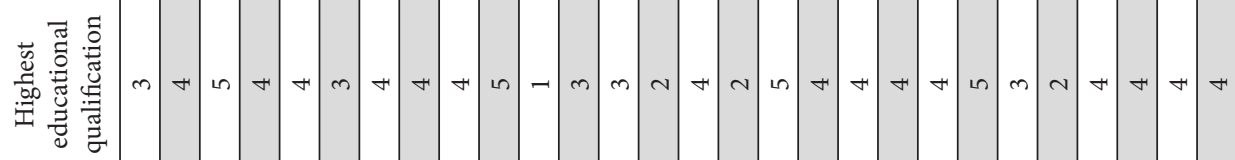

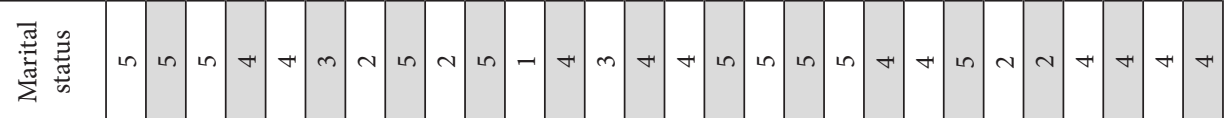

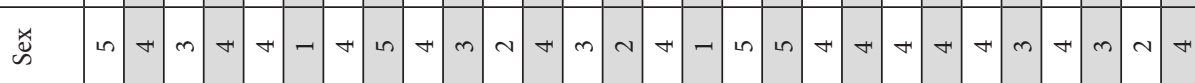

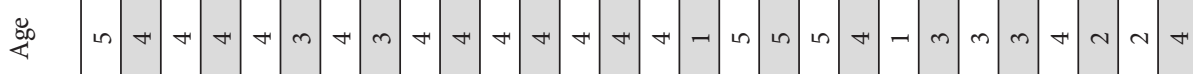

